\title{
Broadly Reactive H2 Hemagglutinin Vaccines Elicit Cross- Reactive Antibodies in Ferrets Preimmune to Seasonal Influenza A Viruses
}

\author{
(D)Z. Beau Reneer, ${ }^{\mathrm{a}, \mathrm{b}}$ (D)Amanda L. Skarlupka, ${ }^{\mathrm{a}, \mathrm{b}}$ Parker J. Jamieson, ${ }^{\mathrm{a}}$ (D)Ted M. Ross ${ }^{\mathrm{a}, \mathrm{b}}$ \\ aCenter for Vaccines and Immunology, University of Georgia, Athens, Georgia, USA \\ bDepartment of Infectious Diseases, University of Georgia, Athens, Georgia, USA
}

ABSTRACT Influenza vaccines have traditionally been tested in naive mice and ferrets. However, humans are first exposed to influenza viruses within the first few years of their lives. Therefore, there is a pressing need to test influenza virus vaccines in animal models that have been previously exposed to influenza viruses before being vaccinated. In this study, previously described $\mathrm{H} 2$ computationally optimized broadly reactive antigen (COBRA) hemagglutinin ( $\mathrm{HA}$ ) vaccines ( $\mathrm{Z} 1$ and $\mathrm{Z5}$ ) were tested in influenza virus "preimmune" ferret models. Ferrets were infected with historical, seasonal influenza viruses to establish preimmunity. These preimmune ferrets were then vaccinated with either COBRA $\mathrm{H} 2 \mathrm{HA}$ recombinant proteins or wild-type $\mathrm{H} 2 \mathrm{HA}$ recombinant proteins in a prime-boost regimen. A set of naive preimmune or nonpreimmune ferrets were also vaccinated to control for the effects of the multiple different preimmunities. All of the ferrets were then challenged with a swine H2N3 influenza virus. Ferrets with preexisting immune responses influenced recombinant $\mathrm{H} 2$ HA-elicited antibodies following vaccination, as measured by hemagglutination inhibition (HAl) and classical neutralization assays. Having both H3N2 and H1N1 immunological memory regardless of the order of exposure significantly decreased viral nasal wash titers and completely protected all ferrets from both morbidity and mortality, including the mock-vaccinated ferrets in the group. While the vast majority of the preimmune ferrets were protected from both morbidity and mortality across all of the different preimmunities, the Z1 COBRA HA-vaccinated ferrets had significantly higher antibody titers and recognized the highest number of $\mathrm{H} 2$ influenza viruses in a classical neutralization assay compared to the other $\mathrm{H} 2 \mathrm{HA}$ vaccines.

IMPORTANCE H1N1 and H3N2 influenza viruses have cocirculated in the human population since 1977. Nearly every human alive today has antibodies and memory B and T cells against these two subtypes of influenza viruses. H2N2 influenza viruses caused the 1957 global pandemic and people born after 1968 have never been exposed to $\mathrm{H} 2$ influenza viruses. It is quite likely that a future $\mathrm{H} 2$ influenza virus could transmit within the human population and start a new global pandemic, since the majority of people alive today are immunologically naive to viruses of this subtype. Therefore, an effective vaccine for $\mathrm{H} 2$ influenza viruses should be tested in an animal model with previous exposure to influenza viruses that have circulated in humans. Ferrets were infected with historical influenza A viruses to more accurately mimic the immune responses in people who have preexisting immune responses to seasonal influenza viruses. In this study, preimmune ferrets were vaccinated with wild-type (WT) and COBRA $\mathrm{H} 2$ recombinant HA proteins in order to examine the effects that preexisting immunity to seasonal human influenza viruses have on the elicitation of broadly cross-reactive antibodies from heterologous vaccination.
Citation Reneer ZB, Skarlupka AL, Jamieson PJ, Ross TM. 2021. Broadly reactive H2 hemagglutinin vaccines elicit cross-reactive antibodies in ferrets preimmune to seasonal influenza A viruses. mSphere 6:e00052-21. https://doi.org/10.1128/mSphere.00052-21. Editor Michael J. Imperiale, University of Michigan-Ann Arbor

Copyright $\odot 2021$ Reneer et al. This is an open-access article distributed under the terms of the Creative Commons Attribution 4.0 International license.

Address correspondence to Ted M. Ross, tedross@uga.edu.

Vaccines for H2N2 influenza viruses are needed since most of the human population is naive to these viruses that caused a pandemic in 1957, circulating until 1968, and still circulate in animals today. These viruses could jump back into humans at any time. @zbeau_32

Received 17 February 2021

Accepted 18 February 2021

Published 10 March 2021 
- he 1957 "Asian Influenza" pandemic was caused by an H2N2 influenza virus resulting in an estimated one to two million deaths worldwide (1). This novel H2N2 influenza virus was the result of a reassortment event between a human $\mathrm{H} 1 \mathrm{~N} 1$ influenza virus and an avian $\mathrm{H} 2 \mathrm{~N} 2$ influenza virus (2). This novel H2N2 influenza virus contained the HA, NA, and PB1 genome segments from an avian H2N2 influenza virus and the other five genome segments from a human H1N1 influenza virus (3). The 1889 influenza pandemic may also have been caused by an H2N2 influenza virus (4). Therefore, as at least one of the last five influenza pandemics was caused by an influenza virus from the H2N2 subtype, it is likely that a future pandemic will be caused by an $\mathrm{H} 2 \mathrm{~N} 2$ influenza virus.

$\mathrm{H} 2$ influenza viruses have not been as extensively studied as other influenza $\mathrm{A}$ virus subtypes, such as $\mathrm{H} 1, \mathrm{H} 3, \mathrm{H} 5$, or $\mathrm{H} 7$. While $\mathrm{H} 2$ influenza viruses have been isolated numerous times from wild avian species and domestic poultry (5-10), there have been no known viral infections of humans since the 1960s. However, in 2006, a novel H2 influenza virus was isolated from two separate swine farms in Missouri (11). This swinederived H2N3 influenza virus has been shown to cause severe disease in both mice and ferrets (12). The $\mathrm{H} 2$ hemagglutinin (HA) is also capable of obtaining a multibasic cleavage site and remaining functional, which could have dire implications for both humans and poultry in the future (13).

The goal of this study was to evaluate how memory immune responses to previous influenza virus infections affect broadly reactive HA-based vaccinations. To develop broadly reactive influenza virus vaccines, our group has used the methodology for enhanced antigen design, termed computationally optimized broadly reactive antigen (COBRA) to design hemagglutinin ( $\mathrm{HA}$ ) immunogens for the $\mathrm{H} 1, \mathrm{H} 3$, and $\mathrm{H} 5$ influenza subtypes (14-21). This process utilizes multiple rounds of layered consensus building to generate influenza virus vaccine $\mathrm{HA}$ antigens that are capable of eliciting broadly reactive $\mathrm{HA}$ antibodies, which can protect against both seasonal and pandemic influenza strains that have undergone genetic drift $(17,18,21)$. These vaccine antigens also inhibit viral infection and virus-induced pathogenesis in mice, ferrets, and nonhuman primates $(16,22-24)$. Using the consensus layering approach of COBRA design, H2 COBRA $\mathrm{HA}$ vaccines were previously developed and characterized (25).

Humans have been infected with different types of influenza viruses throughout their lives (3). Additionally, different subtypes have circulated as seasonal influenza viruses over the past 100 years (3). A person's history of influenza virus infections has an effect on future influenza vaccinations and infections (26-28). The HA subtype from the first influenza virus infection influences the susceptibility of an individual to subsequent influenza virus infections from other subtypes (27). Therefore, a broadly cross-reactive $\mathrm{H} 2$ influenza virus vaccine should be evaluated in animals previously infected or "preimmune" to different influenza virus subtypes.

For this study, Fitch ferrets were infected with different combinations of human isolated H1N1 and H3N2 influenza viruses. These two influenza virus subtypes are the only influenza A viruses that have circulated in the human population since 1968 and would therefore be reflective of the majority of individuals alive today. The H1N1 infections included both a seasonal (before 2009) and a pandemic H1N1 virus (2009 to the present), since individuals alive today who are over the age of 11 would have been exposed to both types of H1N1 influenza viruses. The H1N1 viruses used in this study were Singapore/6/1986 (Sing/86) and California/07/2009 (CA/09), respectively. The H3N2 influenza viruses used to establish preimmunity were either Sichuan/2/1987 (Sich/87) or Panama/2007/1999 (Pan/99). Additionally, the influenza virus preimmunity of individuals alive today would include individuals infected with H1N1 influenza viruses followed by H3N2 influenza viruses and vice versa. Finally, a "nonpreimmune" or "naive preimmune" group was included as a control for the vaccines alone. An H2N2 preimmune group was also included as a pseudo "positive control" group since previous studies have shown that imprinting ferrets with a specific subtype of influenza virus followed by vaccination with another antigenically distinct influenza virus of the same subtype induces expansive 


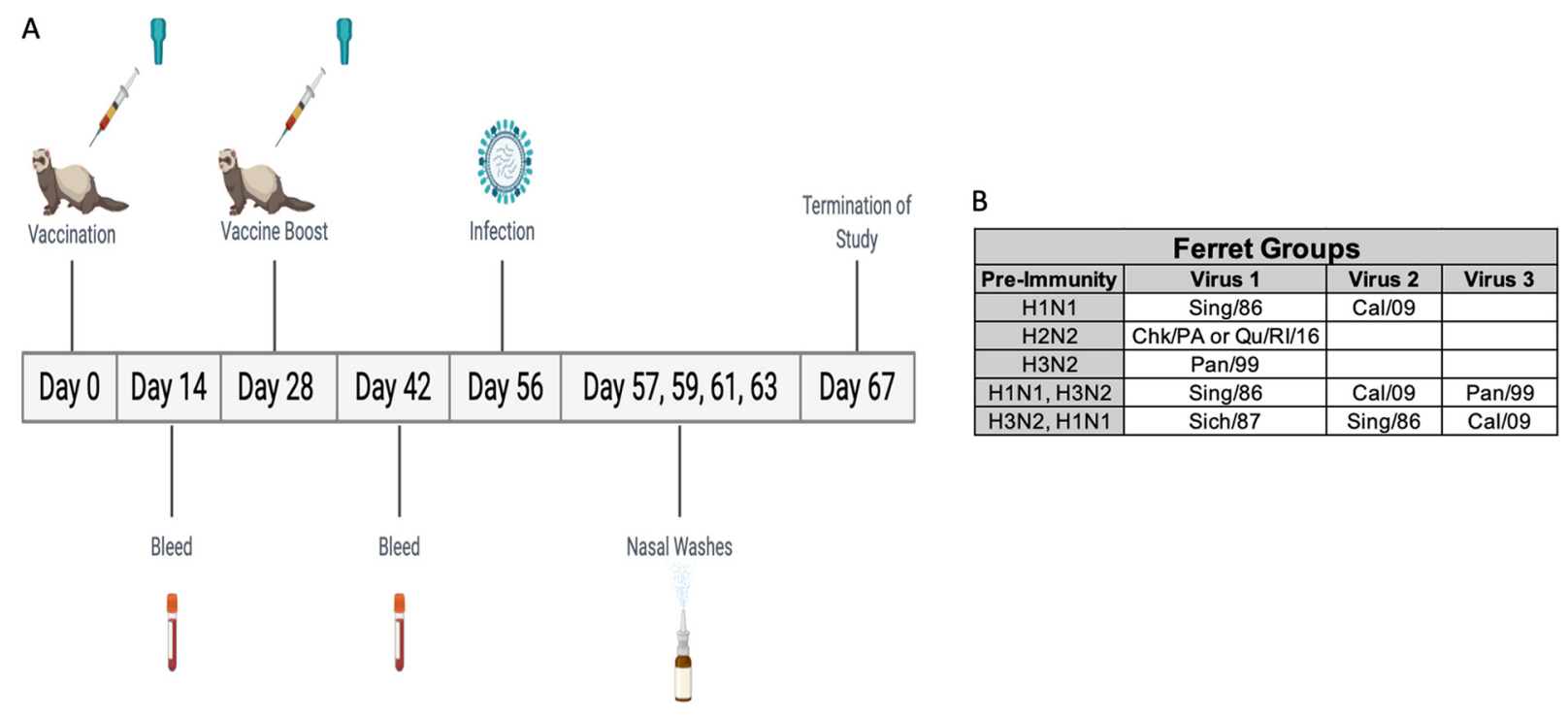

FIG 1 Study outline. A timeline of the procedures following the establishment of preimmunity are listed in panel A. Ferrets were vaccinated at day 0 and day 28. Bleeds were taken at day 14 and day 42 . Ferrets were then infected on day 56 and nasal washes were taken on days $57,59,61$, and 63 . The study was terminated on day 67 . The viruses used to establish different preimmunities are listed in panel $\mathrm{B}$.

intrasubtype antibodies (29). Two antigenically distinct H2N2 avian influenza viruses were used to establish the H2N2 preimmunity because of the restraints of housing ferrets infected with biosafety level 3 (BSL3) human H2N2 influenza viruses in high-level containment for several months.

After preimmunity was established, two H2 COBRA HA vaccines ( $\mathrm{Z} 1$ and $\mathrm{Z5}$ ) were used to vaccinate the ferrets. Protective immune responses elicited by the $\mathrm{Z} 1$ and $\mathrm{Z5}$ COBRA HA vaccines were compared to the elicited response in preimmune ferrets vaccinated with wild-type $\mathrm{H} 2 \mathrm{HA}$ proteins. The Z1 COBRA HA-vaccinated preimmune ferrets showed more broadly cross-reactive antibody responses to a panel of $\mathrm{H} 2$ influenza viruses across each of the six preimmune immune groups compared to ferrets vaccinated with either of the two wild-type H2 HA vaccines. Therefore, the Z1 COBRA HA would be an ideal vaccine for use in individuals regardless of their previous exposure to influenza A viruses.

\section{RESULTS}

Vaccination of ferrets with preexisting influenza virus immunity. Fitch ferrets $(n=20)$ were made preimmune with one of three influenza virus subtypes. The H2N2 preimmunity virus used for infection was either Chk/PA/04 or Qu/RI/16. The H3N2 virus used for infection was either Sich/87 or Pan/99. The H1N1 viruses used for infection were both Sing/86 and CA/09 to represent both seasonal and pandemic H1N1 influenza viruses. After each influenza virus infection, the ferrets were allowed to recover for at least 60 days. Approximately 60 days after the final infection, ferrets had seroconverted to the infection strains with an average HAI titer greater than 1:40 (Fig. S6 in the supplemental material). The H1N1 alone and H3N2-H1N1 and H1N1-H3N2 preimmune groups were then infected with their second virus and allowed to recover for an additional 60 days. The H1N1-H3N2 and the H3N2-H1N1 preimmune groups were then infected with their third virus and allowed to recover for an additional 60 days.

Sixty days after the preimmune groups' final viral infection, the ferrets were vaccinated with $15 \mu \mathrm{g}$ of either wild-type (Mal/NL/01 or Mal/WI/08) or COBRA (Z1 or Z5) H2 recombinant $\mathrm{HA}$ ( $\mathrm{rHA}$ ) proteins (Fig. 1). A comparison of the amino acids in the antigenic sites of wild-type and COBRA HA sequences is shown in Fig. S1. Four ferrets from each of the preimmune groups received the same vaccine (five vaccines with four ferrets each equates to 20 ferrets per preimmunity group). The mock-vaccinated group 
A

H2N2 Pre-Immune WL

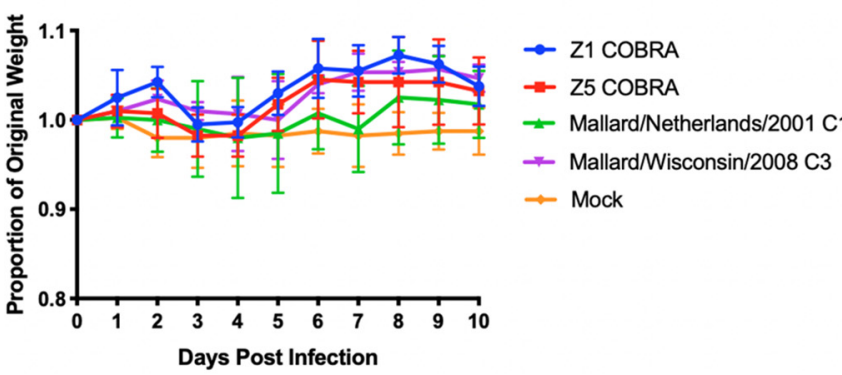

C

H1N1 Pre-Immune WL

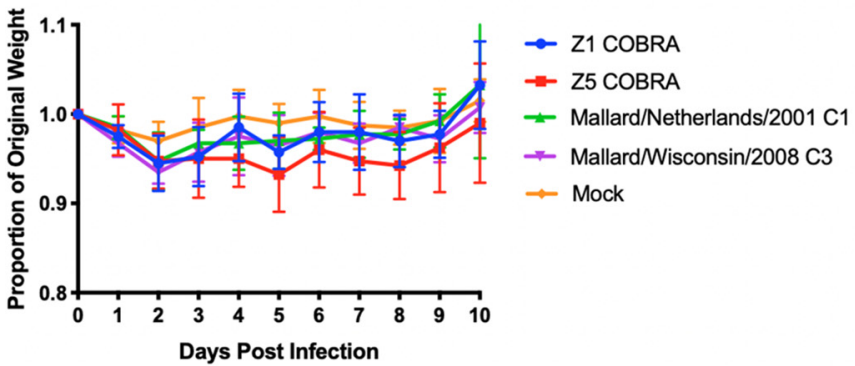

E

H1N1-H3N2 Pre-Immune WL

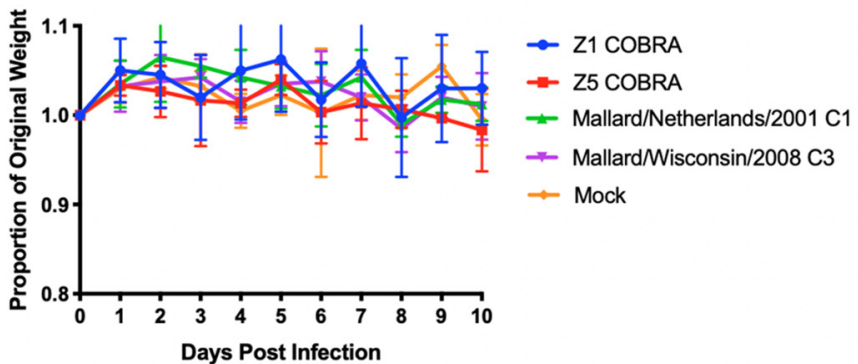

B

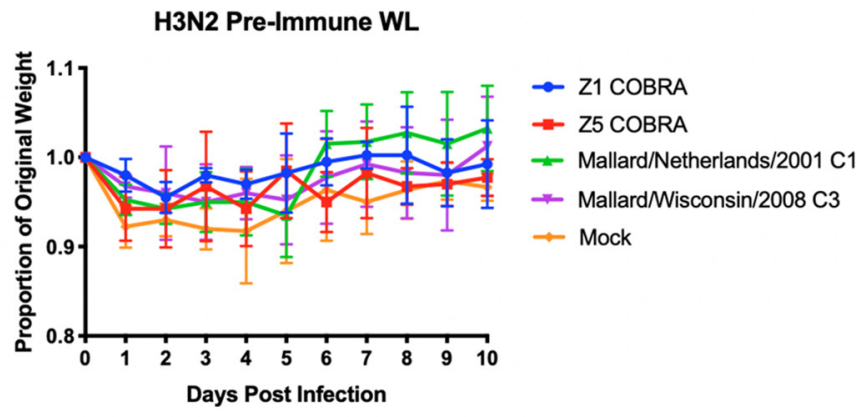

D

H3N2-H1N1 Pre-Immune WL

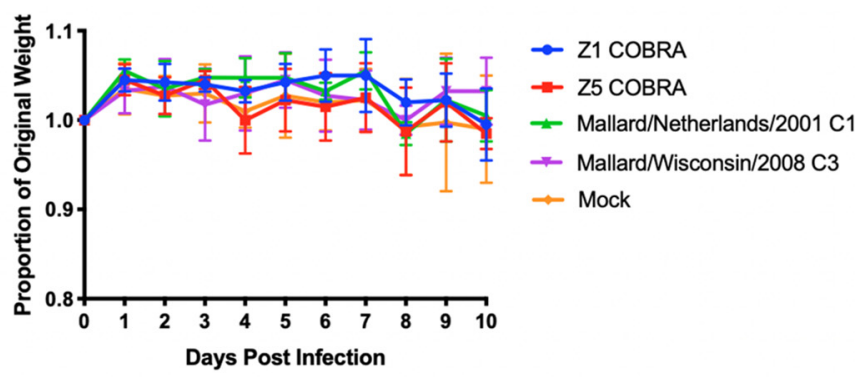

$\mathbf{F}$

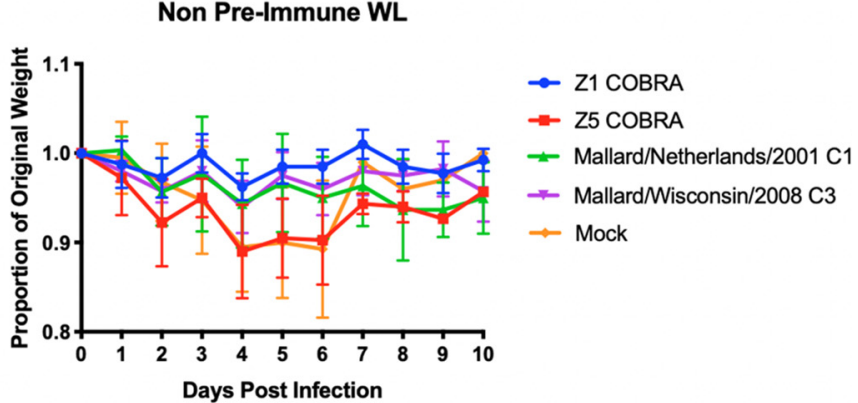

FIG 2 Weight loss of viral-challenged ferrets. Preimmune ferrets vaccinated with wild-type or COBRA rHA vaccines were challenged with Sw/MO/06. Average weight loss was recorded for each vaccine up to 10 days after infection in the H2N2 preimmunity (A), H3N2 preimmunity (B), H1N1 preimmunity (C), H3N2-H1N1 preimmunity (D), H1N1-H3N2 preimmunity (E), and nonpreimmune (F) groups. Error bars represent standard mean error.

was vaccinated with phosphate-buffered saline (PBS) and adjuvant. At 4 weeks after the initial vaccination, the ferrets were vaccinated again with $15 \mu \mathrm{g}$ of the same antigen as the first vaccination. All of the ferrets were bled 2 weeks after each of the vaccinations.

Weight loss and survival. Four weeks after the second vaccination, ferrets were infected with the $\mathrm{H} 2 \mathrm{~N} 3$ clade-3, Sw/MO/06 virus (1e $+6 \mathrm{PFU} / \mathrm{ml})$ (Fig. 1). In the H2N2 preimmune group, there was no significant weight loss after viral challenge and none of the ferrets died (Fig. 2A). In the H3N2 preimmune group, the ferrets in each of the different $\mathrm{H} 2$ rHA vaccination groups had an average weight loss of less than $5 \%$, while the mock-vaccinated $\mathrm{H} 3 \mathrm{~N} 2$ preimmune ferrets reached a peak of $8 \%$ average weight loss on day 4 postinfection (Fig. 2B). The Z5-vaccinated ferrets in the H1N1 preimmune group reached a peak average weight loss of $6 \%$ on day 5 postinfection. None of the other vaccination groups (Mal/NL/01, Mal/Wl/08, or Z1 COBRA) had an average weight loss of greater than $5 \%$ in the H1N1 preimmune group (Fig. $2 \mathrm{C}$ ). The H3N2-H1N1 preimmune ferrets, as well as the H1N1-H3N2 preimmune ferrets, had no detectable average weight loss across any of the four vaccination groups or the mock-vaccinated group after challenge (Fig. 2D and E).

The nonpreimmune ferrets did not have any influenza infection prior to vaccination. 
TABLE 1 Ferret survival percentage ${ }^{a}$

\begin{tabular}{|c|c|c|}
\hline Preimmunity & Vaccine & $\begin{array}{l}\% \text { Survival after Sw/ } \\
\mathrm{MO} / 06 \text { challenge }\end{array}$ \\
\hline $\mathrm{H} 2 \mathrm{~N} 2$ & $\mathrm{Mal} / \mathrm{NL} / 01$ & 100 \\
\hline $\mathrm{H} 2 \mathrm{~N} 2$ & $\mathrm{Mal} / \mathrm{Wl} / 08$ & 100 \\
\hline $\mathrm{H} 2 \mathrm{~N} 2$ & $\mathrm{Z1}$ & 100 \\
\hline $\mathrm{H} 2 \mathrm{~N} 2$ & $\mathrm{Z} 5$ & 100 \\
\hline $\mathrm{H} 2 \mathrm{~N} 2$ & Mock & 100 \\
\hline H3N2 & Mal/NL/01 & 100 \\
\hline $\mathrm{H} 3 \mathrm{~N} 2$ & $\mathrm{Mal} / \mathrm{Wl} / 08$ & 100 \\
\hline $\mathrm{H} 3 \mathrm{~N} 2$ & $\mathrm{Z1}$ & 100 \\
\hline $\mathrm{H} 3 \mathrm{~N} 2$ & $\mathrm{Z5}$ & 100 \\
\hline $\mathrm{H} 3 \mathrm{~N} 2$ & Mock & 75 \\
\hline $\mathrm{H} 1 \mathrm{~N} 1$ & Mal/NL/01 & 100 \\
\hline $\mathrm{H} 1 \mathrm{~N} 1$ & $\mathrm{Mal} / \mathrm{Wl} / 08$ & 100 \\
\hline H1N1 & $\mathrm{Z} 1$ & 100 \\
\hline $\mathrm{H} 1 \mathrm{~N} 1$ & $\mathrm{Z5}$ & 100 \\
\hline H1N1 & Mock & 100 \\
\hline $\mathrm{H} 3 \mathrm{~N} 2, \mathrm{H} 1 \mathrm{~N} 1$ & $\mathrm{Mal} / \mathrm{NL} / 01$ & 100 \\
\hline $\mathrm{H} 3 \mathrm{~N} 2, \mathrm{H} 1 \mathrm{~N} 1$ & $\mathrm{Mal} / \mathrm{Wl} / 08$ & 100 \\
\hline $\mathrm{H} 3 \mathrm{~N} 2, \mathrm{H} 1 \mathrm{~N} 1$ & $\mathrm{Z1}$ & 100 \\
\hline $\mathrm{H} 3 \mathrm{~N} 2, \mathrm{H} 1 \mathrm{~N} 1$ & Z5 & 100 \\
\hline $\mathrm{H} 3 \mathrm{~N} 2, \mathrm{H} 1 \mathrm{~N} 1$ & Mock & 100 \\
\hline $\mathrm{H} 1 \mathrm{~N} 1, \mathrm{H} 3 \mathrm{~N} 2$ & $\mathrm{Mal} / \mathrm{NL} / 01$ & 100 \\
\hline $\mathrm{H} 1 \mathrm{~N} 1, \mathrm{H} 3 \mathrm{~N} 2$ & $\mathrm{Mal} / \mathrm{Wl} / 08$ & 100 \\
\hline $\mathrm{H} 1 \mathrm{~N} 1, \mathrm{H} 3 \mathrm{~N} 2$ & $\mathrm{Z1}$ & 100 \\
\hline $\mathrm{H} 1 \mathrm{~N} 1, \mathrm{H} 3 \mathrm{~N} 2$ & $\mathrm{Z5}$ & 100 \\
\hline $\mathrm{H} 1 \mathrm{~N} 1, \mathrm{H} 3 \mathrm{~N} 2$ & Mock & 100 \\
\hline Mock & $\mathrm{Mal} / \mathrm{NL} / 01$ & 100 \\
\hline Mock & $\mathrm{Mal} / \mathrm{Wl} / 08$ & 100 \\
\hline Mock & $\mathrm{Z1}$ & 100 \\
\hline Mock & $\mathrm{Z5}$ & 75 \\
\hline Mock & Mock & 25 \\
\hline
\end{tabular}

aThe survival rate among ferrets in each of the vaccination groups across all of the preimmunities. The columns correspond to the preimmunity, the vaccine, and the survival percentage after challenge with A/Swine/ Missouri/4296424/2006 (Sw/MO/06) (H2N3). Each row is a vaccination group with its preimmunity followed by the survival percentage following viral challenge. Ferret groups contained either $n=3$ or $n=4$ ferrets.

Both the Z5- and mock-vaccinated ferrets reached a peak average weight loss of $>10 \%$ by day 4 postinfection (Fig. 2F). The Mal/NL/01- and Mal/Wl/08-vaccinated groups reached a peak average weight loss of $\sim 5 \%$ on day 4 postinfection. The Z1-vaccinated group had a peak average weight loss of $\sim 3 \%$ on day 4 postinfection. The Mal/NL/01-, Mal/Wl/08-, and Z1-vaccinated ferrets all survived until the end of the study. The mock- and Z5-vaccinated groups had significantly more weight loss than the Z1-vaccinated ferrets on days 4,5 , and 6 ( $P<0.01$ for mock and $P<0.05$ for Z5). The mock- and Z5-vaccinated groups also had significantly more weight loss than the $\mathrm{Mal} / \mathrm{Wl} / 08$-vaccinated ferrets on day $5(P<0.05)$. These were the only statistically significant differences in weight loss between vaccination groups in any of the preimmune groups.

Only the nonpreimmune and $\mathrm{H} 3 \mathrm{~N} 2$ preimmune groups experienced mortality. For the nonpreimmune group, one of the Z5-vaccinated ferrets reached humane endpoint by day 6 postinfection (Table 1). Also in the nonpreimmune group, three of the four ferrets in the mock-vaccinated group reached humane endpoint by day 6 postinfection (Table 1). In the H3N2 preimmune group, one ferret in the mock-vaccinated group had to be euthanized on day 5 postinfection (Table 1 ).

Viral titers. In the H2N2 preimmune group, one ferret in both the Z5- and mockvaccinated groups had viral titers of $\sim 1.0 \mathrm{e}+3 \mathrm{PFU} / \mathrm{ml}$ on day 1 . One ferret each of the Mal/NL/01-, Z5-, and mock-vaccinated groups had detectable viral titers in their nasal washes at day 3. There were no detectable viral titers in any ferret in the day 5 or day 7 
nasal washes (Fig. 3A to D). In the H3N2 preimmune group, one ferret in each of the $\mathrm{Mal} / \mathrm{NL} / 01, \mathrm{Z1}$, and Z5 vaccination groups had viral titers on day 1 (between $1 \mathrm{e}+2$ and $1 e+3$ ) (Fig. 3E). The mock-vaccinated group had two ferrets with viral titers around $1 \mathrm{e}+4$, while the Mal/Wl/08 ferrets had no detectable titers. On day 3 postinfection, one ferret in each of the vaccination groups besides the mock vaccination group had viral titers between $5 e+2$ and $5 e+3 \mathrm{PFU} / \mathrm{ml}$. The mock-vaccinated ferrets had no detectable titers on day 3 (Fig. 3F). On day 5 postinfection, only one ferret in the mock-vaccinated group had detectable viral titers (Fig. 3G). This mock-vaccinated ferret also reached humane endpoint on day5 (Table 1). None of the H3N2 preimmune ferrets had detectable viral titers on day 7 postinfection (Fig. $3 \mathrm{H}$ ).

None of the ferrets in the $\mathrm{H} 1 \mathrm{~N} 1$ preimmune group had detectable viral titers in their nasal washes on days 1, 5, or 7 postinfection (Fig. 3l, $\mathrm{K}$ to $\mathrm{L}$ ). All five of the vaccination groups had at least one ferret with detectable viral titers in their nasal washes on day 3. The mock-vaccinated ferrets had the highest average viral titers $(\sim 1 \mathrm{e}+3 \mathrm{PFU} / \mathrm{ml})$, while the other four vaccination groups had average viral titers between $5 e+1$ and 5 e +2 PFU/ml (Fig. 3J).

In the nonpreimmune group, multiple ferrets in Mal/NL/01, Mal/Wl/08, Z5, and mock vaccination groups all had detectable viral titers in their day 1 nasal washes, with multiple ferrets in each of the vaccination groups having $\geq 3 e+1$ viral titers. None of the ferrets in the $\mathrm{Z} 1$ vaccination group had detectable viral titers on day 1 postinfection (Fig. 3M). On day 3 postinfection, the average viral titers for the Mal/NL/01-, Mal/ WI/08-, Z5-, and mock-vaccinated ferrets all had average viral titers between $\sim 1 \mathrm{e}+3$ and $1 \mathrm{e}+4$. One ferret in the $\mathrm{Z} 1$ vaccination group had detectable viral titers on day 3 postinfection (Fig. $3 \mathrm{~N}$ ). On day 5 postinfection, multiple ferrets in the Mal/NL/01-, Mal/ WI/08-, Z5-, and mock-vaccinated groups had viral titers $>1 e+2$, with the mock-vaccinated ferrets having the highest average viral titer of $\sim 1 e+3$. None of the ferrets in the $\mathrm{Z1}$ vaccination group had detectable viral titers on day 5 postinfection (Fig. 30). None of the surviving ferrets had detectable viral titers in their nasal washes on day 7 postinfection (Fig. 3P). None of the ferrets in the H3N2-H1N1 preimmune or the H1N1$\mathrm{H} 3 \mathrm{~N} 2$ preimmune groups had any detectable viral titers in their nasal washes on any day (Fig. S7). Of all the time points and preimmunity backgrounds, there was no significant difference between the vaccinated groups and the mock groups except for nonpreimmune day $1 \mathrm{NW}$, where Z1 was significantly lower than the mock group with a $P$ value of 0.0078 using a one-way ANOVA plus Tukey's test.

A three-way ANOVA looking at the main effects of vaccine received, the ferret preimmunity, and the day of the nasal wash indicated that overall, when adjusting for preimmunity and day postinfection, that the mean viral nasal wash titers of the Z1 COBRA was significantly lower than that of the mock-vaccinated group by 0.322 log 10 viral titer $(P$ adjusted $<0.001)$. Furthermore, the Z1 COBRA also had a titer of $0.219 \log 10$ lower after adjustment compared to the Z5 COBRA ( $P$ adjusted $=0.039$ ) (Fig. S2). Only the nonpreimmune ferrets were significantly different from the other preimmunities after controlling for vaccine received and day postinfection (Fig. S2). All other preimmunities had nonsignificant mean viral titers. When comparing the day postinfection, day 1 and day 3 were not significantly different, but day 5 had lower viral titers compared to either day 3 or day 1.

Hemagglutination-inhibition (HAI) antibodies. The HAl titers varied greatly between the preimmune groups. The $\mathrm{H} 2 \mathrm{~N} 2$ preimmune ferrets were the only preimmune group to have HAl titers to virus-like particles (VLPs) in the $\mathrm{H} 2$ panel on the day of prime vaccination (Fig. 4). Ferrets in all five of the vaccination groups had average HAl titers above 1:40 to multiple VLPs in the $\mathrm{H} 2$ panel, but none of the vaccination groups had detectable titers to all 12 of the H2 HA VLPs (Fig. 4).

After the first vaccination, the $\mathrm{H} 2 \mathrm{~N} 2$ preimmune ferrets had a geometric mean $\mathrm{HAl}$ titer of $\geq 1: 40$ to all 12 of the VLPs in the panel excluding the mock vaccination group (Fig. 5A to E). The H3N2 preimmune ferrets had low HAl titers to the H2 VLPs after the first vaccination (Fig. $5 \mathrm{~F}$ to J). Only the $\mathrm{Z1}$-vaccinated ferrets had a geometric mean $\mathrm{HAI}$ 
A

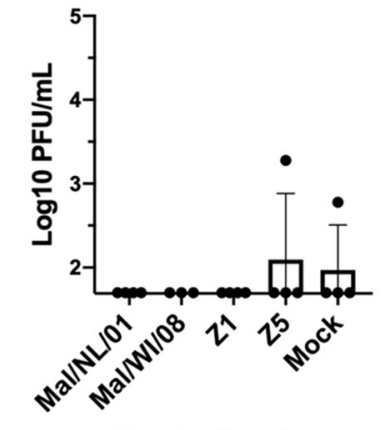

Vaccination Group

E

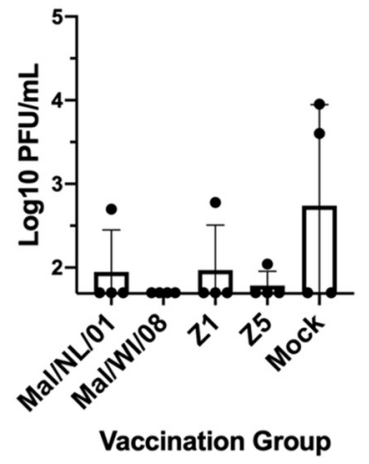

I

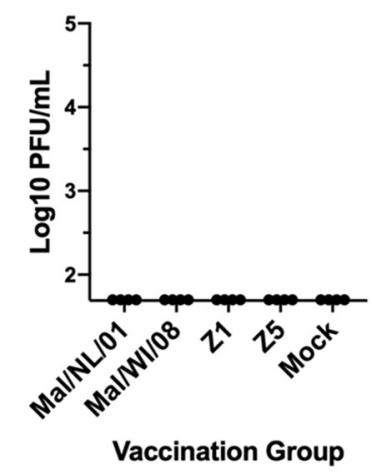

M

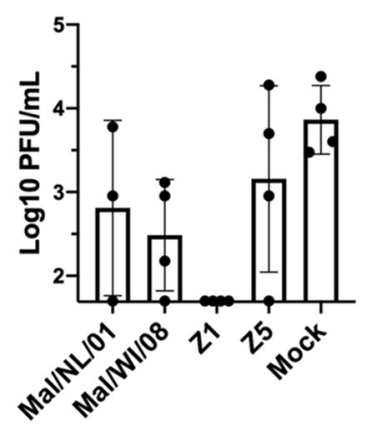

Vaccination Group
B

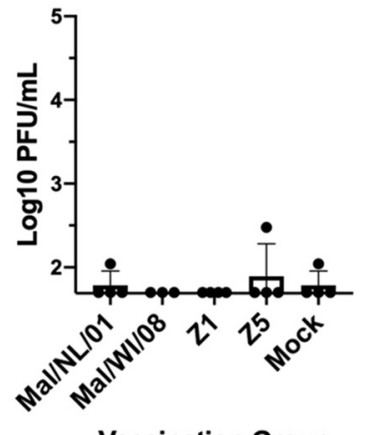

$\mathbf{F}$

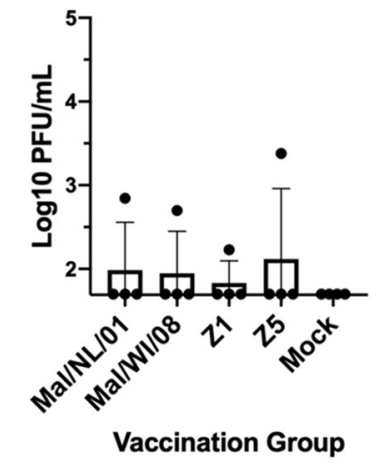

C

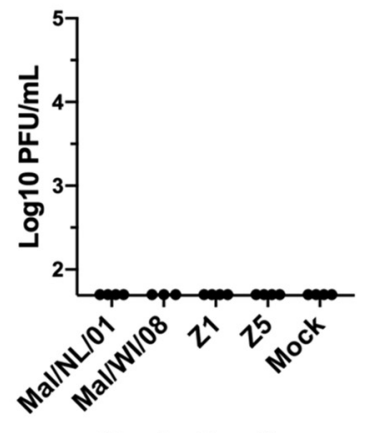

Vaccination Group

G H3N2 Pre-Immune D5 NW

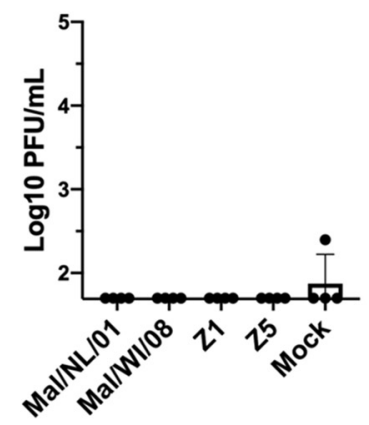

Vaccination Group
D H2N2 Pre-immune D7 NW

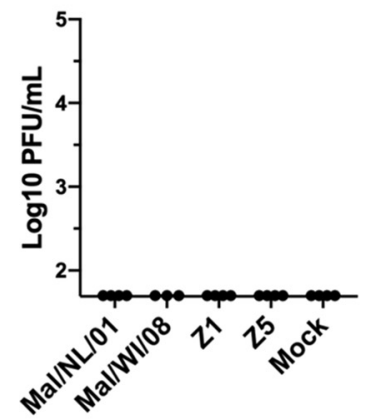

Vaccination Group

H H3N2 Pre-Immune D7 NW

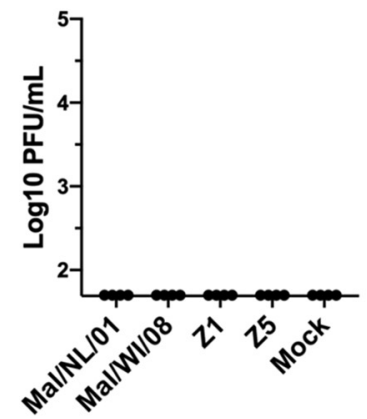

Vaccination Group

$\mathbf{K}$

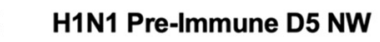

L H1N1 Pre-Immune D7 NW
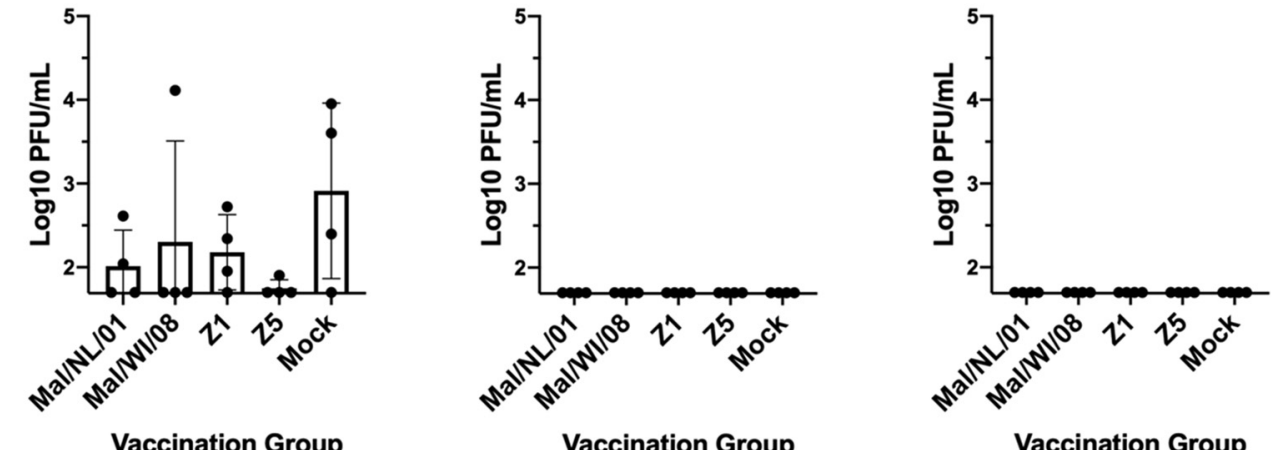

Vaccination Group

O

Vaccination Group

N Non Pre-Immune D3 NW

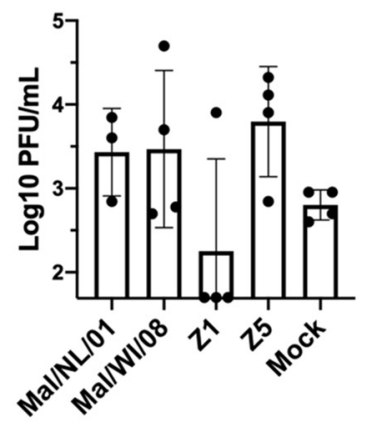

Vaccination Group

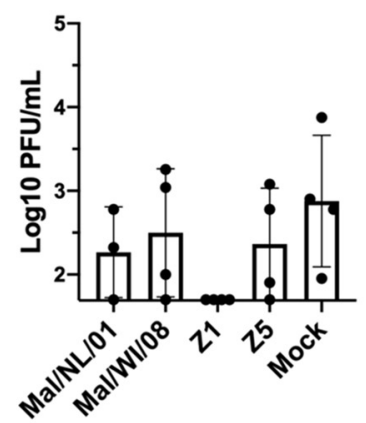

Vaccination Group
P Non Pre-Immune D7 NW

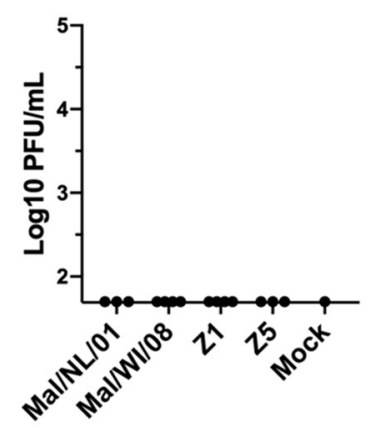

Vaccination Group

FIG 3 Viral nasal wash titers. Nasal washes were performed on days 1, 3, 5 and 7 postinfection. The titers are recorded as log ${ }_{10}$ PFU/ml. The $\mathrm{H} 2 \mathrm{~N} 2$ preimmune ferrets are shown in panels A to D. The H3N2 preimmune ferrets are shown in panels $E$ to $H$. The H1N1 preimmune ferrets are shown in panels I to L. The nonpreimmune ferrets are shown in panels $M$ to $P$. The height of the bars shows the mean while the error bars represent mean standard error. 
A
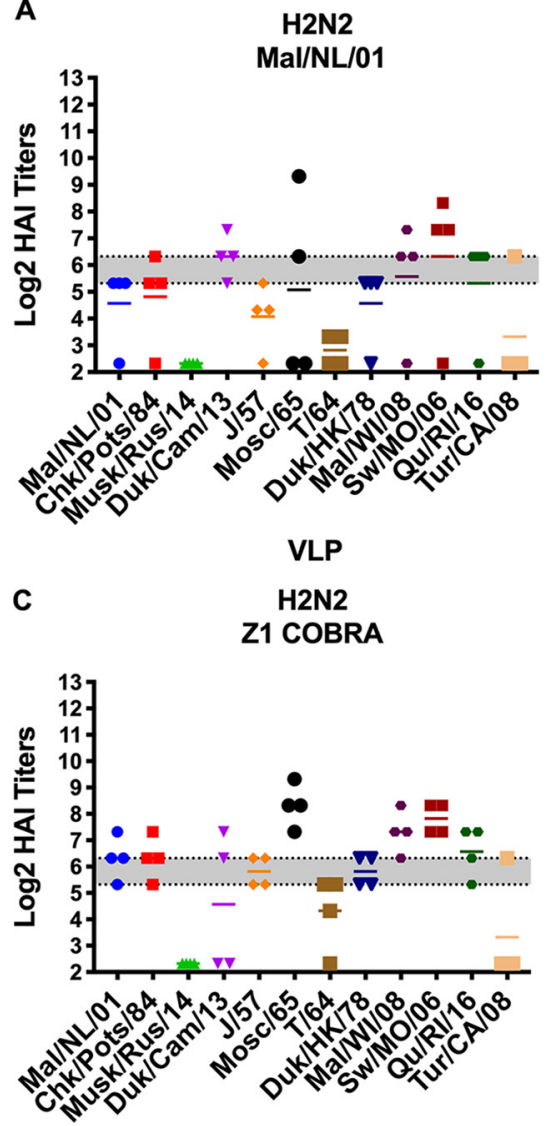

VLP

E

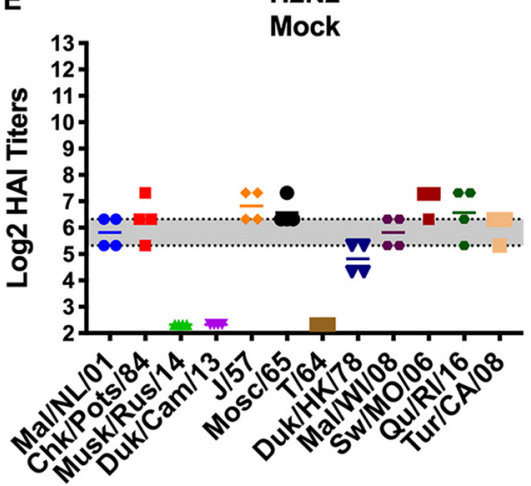

VLP
B

B $\begin{gathered}\mathrm{H} 2 \mathrm{~N} 2 \\ \mathrm{Mal} / \mathrm{WI} / 08\end{gathered}$

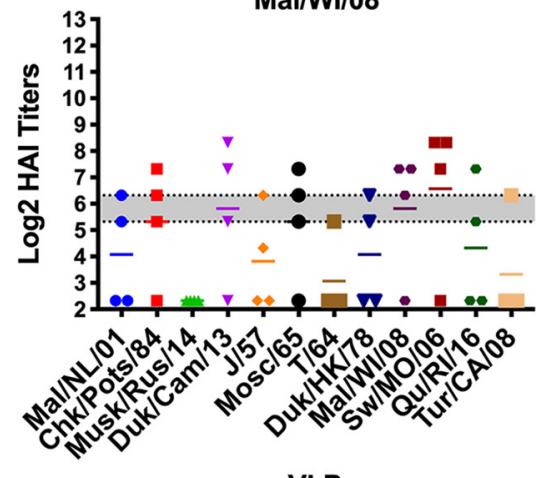

VLP

D

H2N2

Z5 COBRA

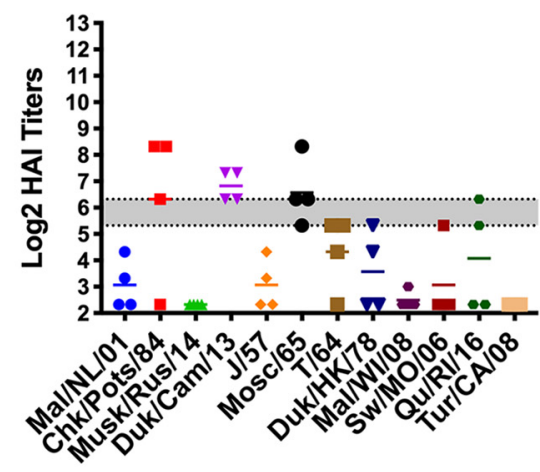

VLP

FIG 4 Cross-reactive antibody responses on day 0 (prime vaccination) in H2N2 preimmune ferrets. HAl titers are given for each vaccine group in the H2N2 preimmunity. Serum from each ferret was obtained on the day of prime vaccination (60 days postinfection) and tested against VLPs expressing 12 WT H2 HA sequences. Dotted lines indicate 1:40 and 1:80 HAI titers, respectively. The VLP panel is composed of: clade-1 HAs (Mallard/Netherlands/2001, Chicken/Potsdam/1984, Muskrat/Russia/2014, and Duck/Cambodia/2013), clade-2 HAs (Duck/Hong Kong/1978, Taiwan/1/1964, Moscow/1019/1965, and Japan/305/1957), and clade-3 HAs (Mallard/Wisconsin/2008, Swine/Missouri/2006, Quail/Rhode Island/2016, and Turkey/California/2008). Error bars represent standard mean errors.

titer of $\geq 1: 40$ to more than one H2 VLP (Fig. $5 H$ ). The mock-vaccinated ferrets in H1N1 preimmune group did not have detectable HAI titers to any of the H2 VLPs after the first vaccination. The Mal/NL/01-, Mal/Wl/08-, and Z1-vaccinated ferrets had geometric mean HAI titers of $\geq 1: 40$ against multiple $H 2$ VLPs after the first vaccination (Fig. $5 \mathrm{~K}, \mathrm{~L}$, 


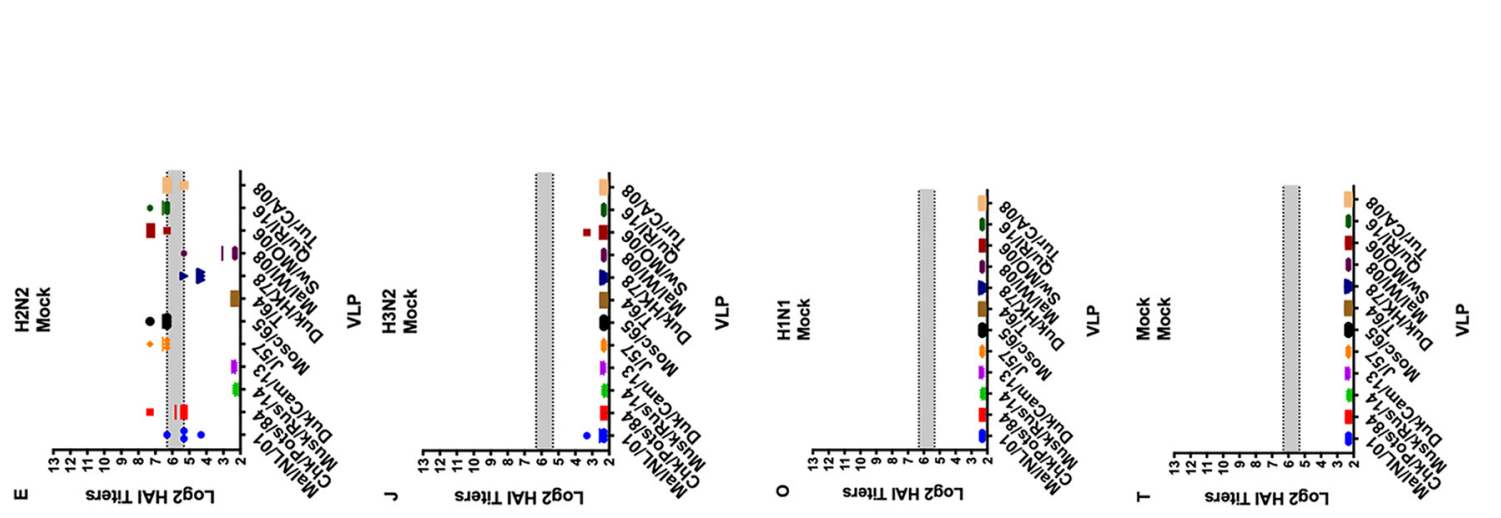

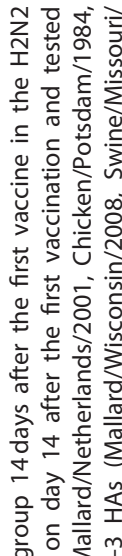
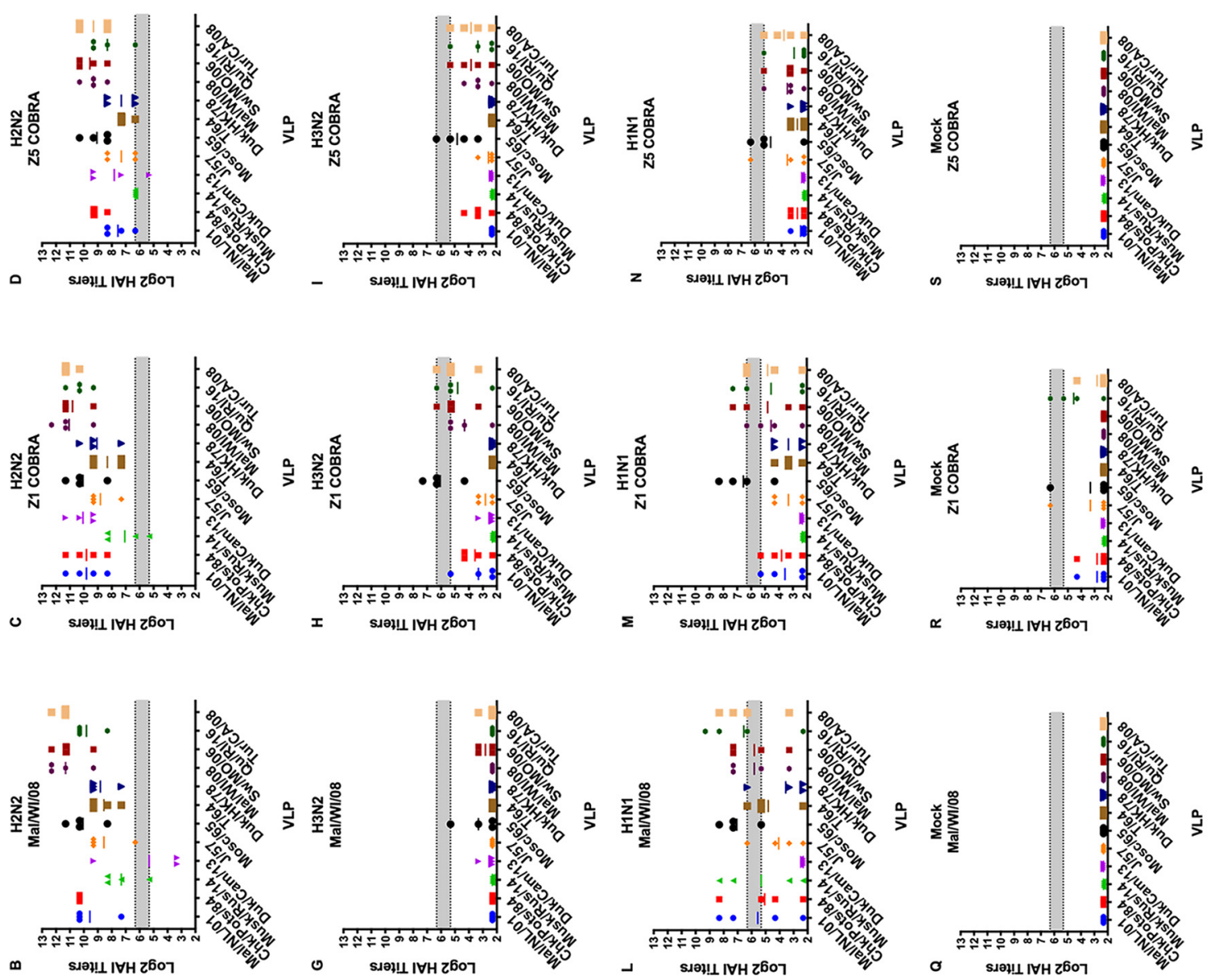

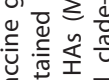

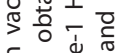

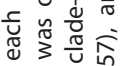

훈

षे छ

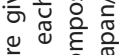

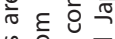

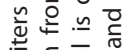

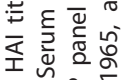

ธ่ํำ

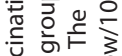

宁 $F \dot{\overline{0}}$

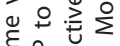

훈 웡

○े है

ป.

츙 은

둥

윽 둥

응 ठ

오운ㅎㅇㅇ

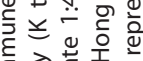

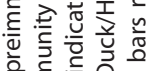

है है

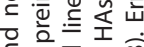

整

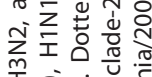

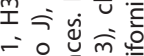

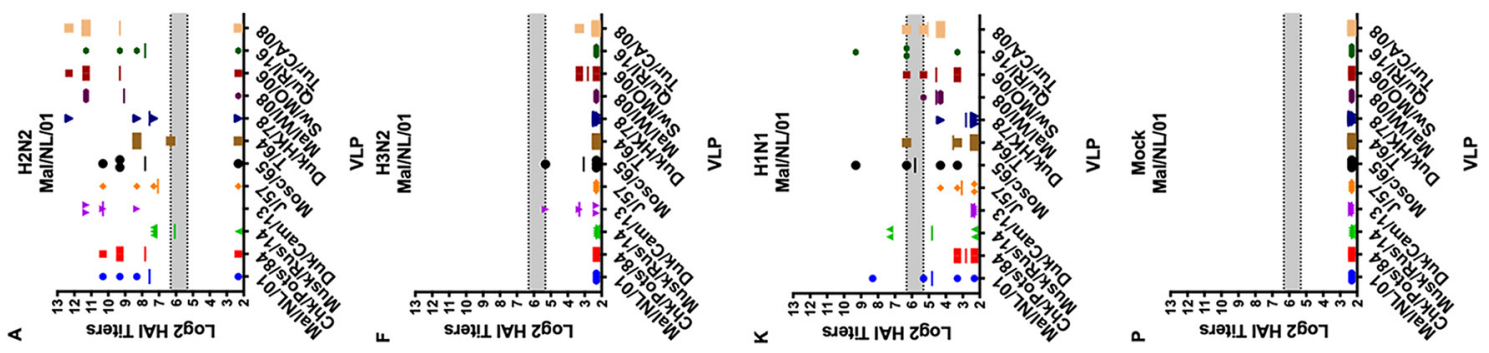

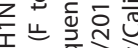

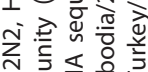

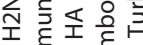

Ч。

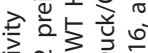

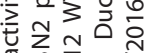

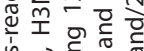

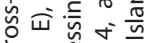

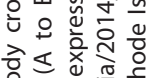

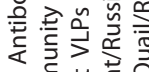

in है है व

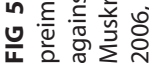


$\mathrm{N}$, and $\mathrm{O}$ ). The Z5-vaccinated H1N1 preimmune ferrets only had geometric mean HAI titers of $\geq 1: 40$ against one H2 VLP (Fig. 5M). The nonpreimmune ferrets in the Mal/NL/ 01, Mal/Wl/08, Z5, and mock vaccination groups had no detectable HAl titers after the first vaccination (Fig. 5P, Q, S, and T). The Z1-vaccinated ferrets had some HAl titers after the first vaccination, but none of them reached a geometric mean titer of 1:40 (Fig. 5R).

After the second vaccination, the HAl titers for the ferrets in the H2N2 preimmune group did not drastically change (Fig. 6A to E). In the H3N2 preimmune group, HAI titers in the Mal/NL/01-, Mal/WI/08-, Z1-, and Z5-vaccinated ferrets all increased significantly after the second vaccination. This was the only statistically significant increase in average titer using multiple $t$ test analyses comparing for the change in each vaccine titer between days 14 and 42 post-prime vaccination. Each of these four vaccination groups had HAl titers of $\geq 1: 40$ to seven or more VLPs in the panel. The Z1- and Z5-vaccinated ferrets had geometric mean HAI titers of $\geq 1: 80$ to 9 and 10 of the 12 VLPs in the panel, respectively (Fig. $6 \mathrm{~F}$ to $\mathrm{J}$ ).

In the H1N1 preimmune ferrets, the HAl titers of all of the vaccination groups besides the mock vaccination group increased after the second vaccination (Fig. $6 \mathrm{~K}$ to O). After the second vaccination, the Mal/WI/08 vaccination group had geometric mean HAl titers of $\geq 1: 40$ to seven of the 12 VLPs in the panel. The Mal/NL/01-, Z1-, and Z5-vaccinated ferrets all had geometric mean HAl titers of $>1: 40$ to 10 or more of the VLPs in the $\mathrm{H} 2$ panel. The Mal/NL/01- and the Mal/WI/08-vaccinated ferrets had a geometric mean HAl titer of $\geq 1: 80$ to seven and six of the 12 VLPs in the $\mathrm{H} 2$ panel, respectively. The Z1- and Z5-vaccinated ferrets had geometric mean HAI titers of $\geq 1: 80$ to nine of the 12 VLPs in the $\mathrm{H} 2$ panel.

In the nonpreimmune group, the $\mathrm{HAl}$ titers in the Mal/NL/01, Mal/Wl/08, Z1, and Z5 vaccination groups all increased after the second vaccination (Fig. $6 \mathrm{P}$ to $\mathrm{T}$ ). The Mal/ $\mathrm{NL} / 01$ - and Mal/WI/08-vaccinated ferrets had geometric mean HAl titers of $\geq 1: 40$ to 3 and 5 of the VLPs in the $\mathrm{H} 2$ panel. The Z1- and Z5-vaccinated ferrets had geometric mean HAl titers of $\geq 1: 40$ to 11 and 9 of the VLPs, respectively. The Mal/NL/01-, Mal/WI/ 08-, and Z5-vaccinated ferrets had geometric mean HAl titers of $\geq 1: 80$ to 2,4 , and 5 of the $\mathrm{H} 2$ VLPs in the panel, respectively. The Z1-vaccinated ferrets had geometric mean $\mathrm{HAl}$ titers of $\geq 1: 80$ to 10 of the 12 VLPs in the $\mathrm{H} 2$ panel.

The H3N2-H1N1 and the H1N1-H3N2 preimmune groups varied greatly in their HAI responses. The H3N2-H1N1 preimmune group had little to no HAl titers after the first vaccination to any of the VLPs in the panel (Fig. 7A to E). The H1N1-H3N2 preimmune group had multiple ferrets in each vaccination group with detectable $\mathrm{HAl}$ titers to each of the 12 VLPs in the panel (Fig. 7F to J). The Z5 and Mal/NL/01 vaccination groups had a geometric mean $\mathrm{HAl}$ titer of $>1: 40$ to 7 and 8 of the VLPs in the panel, respectively. The Mal/Wl/08 and Z1 vaccination groups had a geometric mean HAl titer of $\geq 1: 40$ to 11 and 12 out of the 12 VLPs in the panel, respectively.

After the second vaccination, the Z5- and Z1-vaccinated ferrets in the H3N2-H1N1 preimmune group had HAl titers of $\geq 1: 40$ to 5 and 6 of the VLPs in panel, respectively. The Mal/NL/01- and the Mal/WI/08-vaccinated ferrets had HAl titers of $\geq 1: 40$ to 9 and 10 of the 12 VLPs in the panel, respectively (Fig. $8 \mathrm{~A}$ to E). After the second vaccination for the H1N1-H3N2 preimmune group, the Z5-vaccinated ferrets had a geometric mean HAI titer of $\geq 1: 40$ to 10 of the VLPs, while the Z1-vaccinated ferrets had a geometric mean HAl titer of $\geq 1: 40$ to all 12 of the VLPs in the panel. The Mal/NL/01 and $\mathrm{Mal} / \mathrm{WI} / 08$ vaccination groups had a geometric mean $\mathrm{HAl}$ titer of $\geq 1: 40$ to 11 of the VLPs in the panel (Fig. 8F to J).

After controlling for the main effects of the vaccine received, preexisting immunity, and HAI VLP, the Z1 COBRA vaccine had a significantly higher overall $\log _{2}$ mean HAI titer compared to the other vaccine groups using an ANOVA with Tukey adjustment method. The Z5 COBRA and Mal/WI/08 vaccines were not significantly different from each other, and the Mal/NL/01 vaccine titers were significantly lower than the other vaccine groups. For preimmunity, the ferrets with an H2N2 background had a 


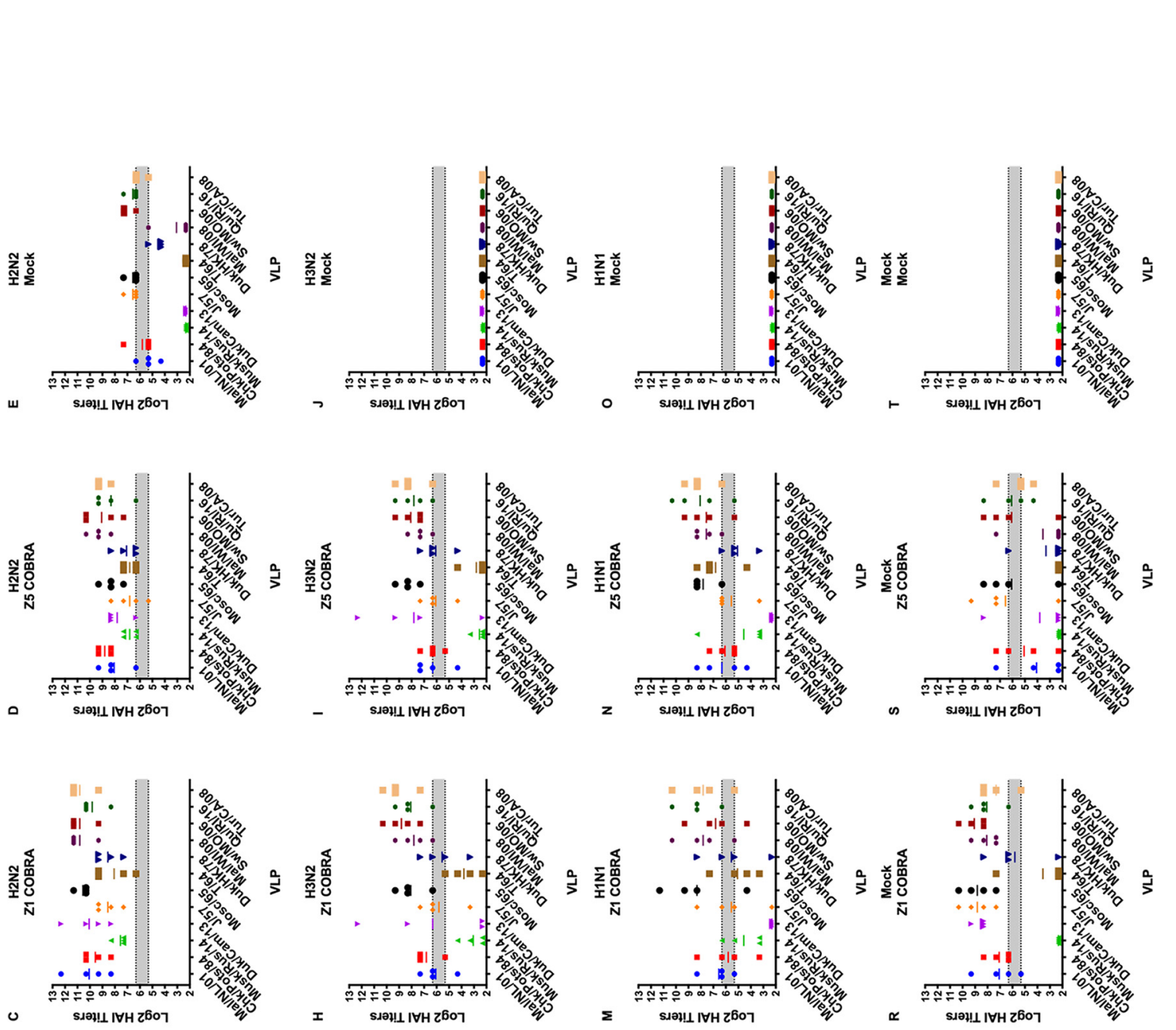

흥 을 휳

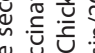

每

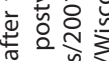

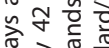

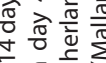

o c。

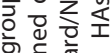

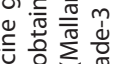

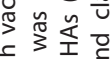

『ँ

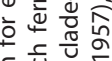

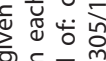

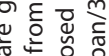

品

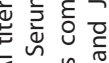

空高次

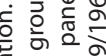

它F产

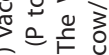

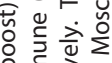

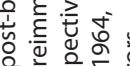

寸

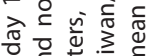

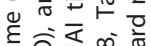

훙에

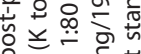

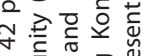

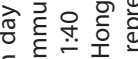

ธ
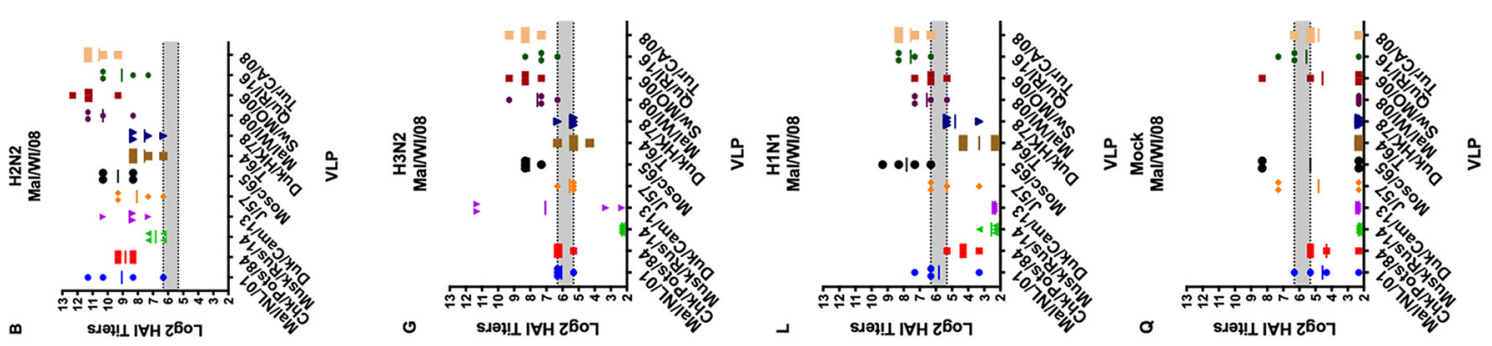

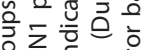

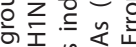

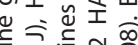

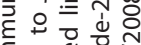

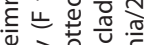

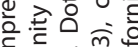

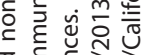

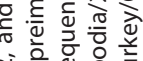

N

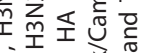

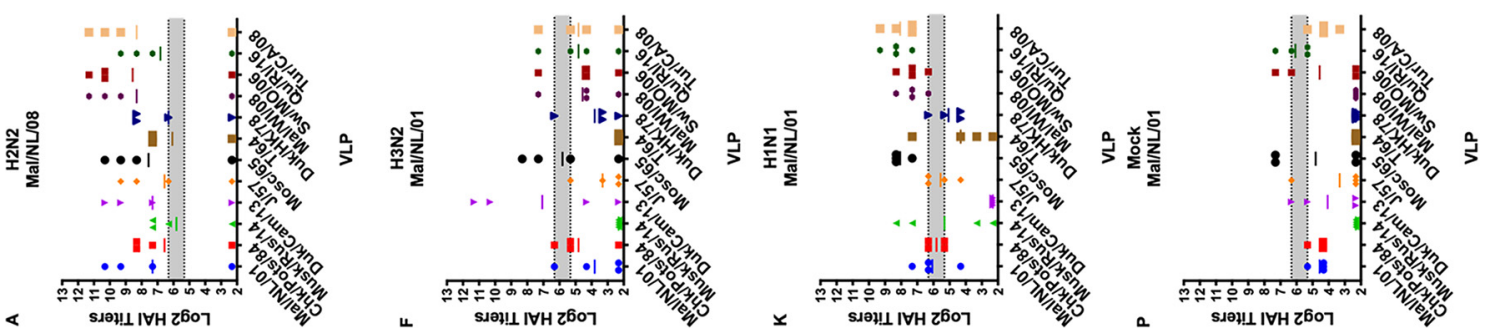

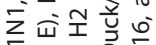

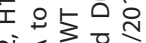

눧ㅇ

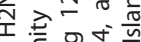

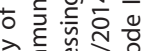

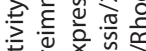

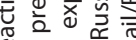

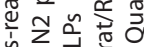

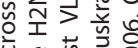

论㟥定

웡

产 을 월

0.

는 范完 


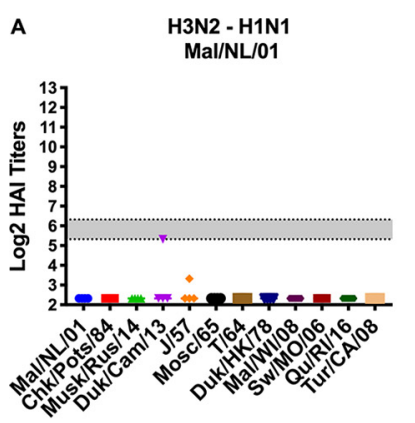

VLP

B H3N2 - H1N

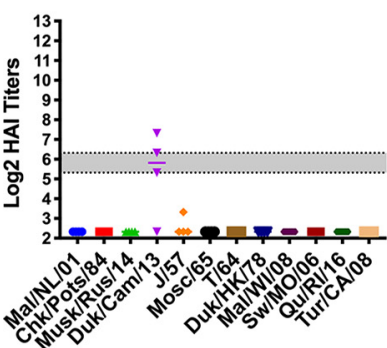

VLP

c
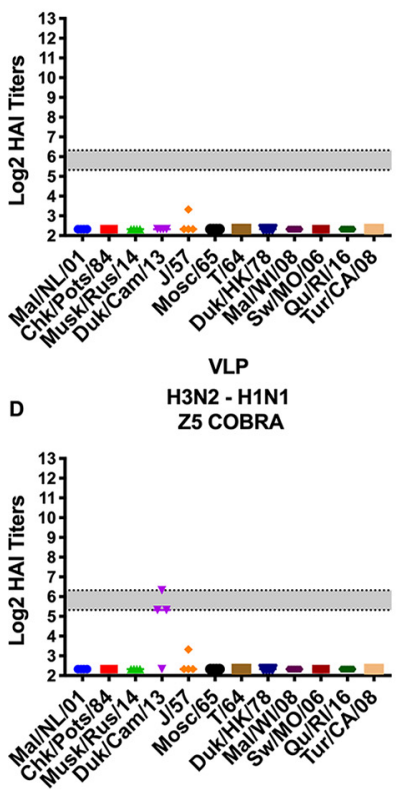

VLP
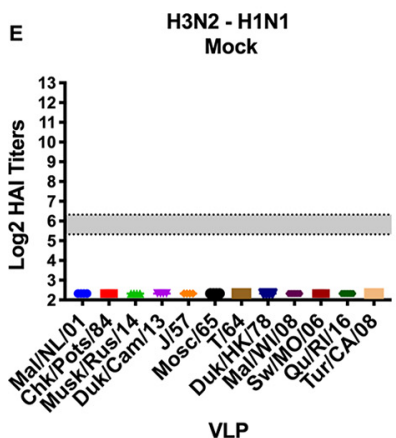

F $\begin{gathered}\text { H1N1 - H3N2 } \\ \text { Mal/NL/01 }\end{gathered}$

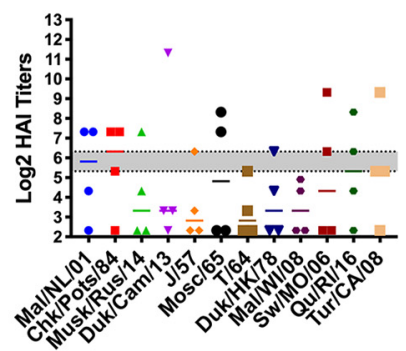

VLP
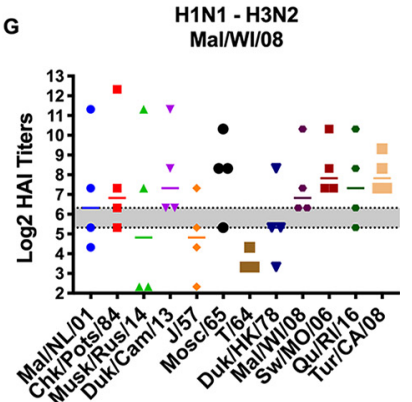

VLP

H $\begin{gathered}\text { H1N1 - H3N2 } \\ \text { Z1 COBRA }\end{gathered}$

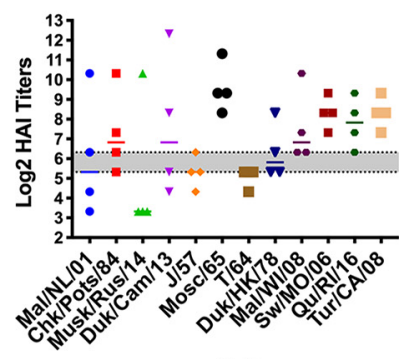

VLP

H1N1 - H3N2

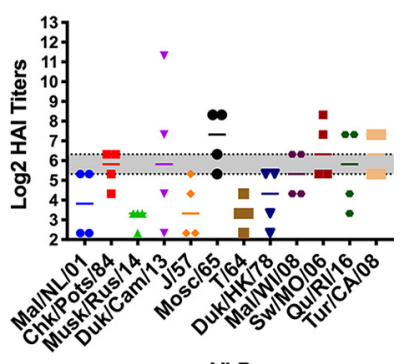

VLP
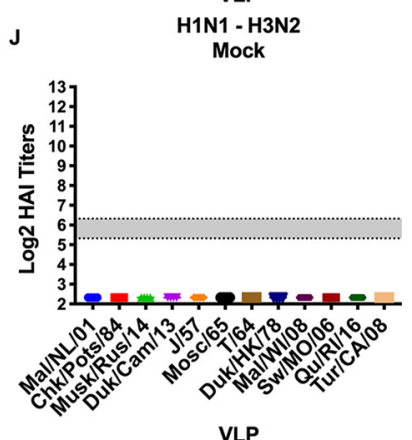

FIG 7 Antibody cross-reactivity of $\mathrm{H} 1 \mathrm{~N} 1-\mathrm{H} 3 \mathrm{~N} 2$ and $\mathrm{H} 3 \mathrm{~N} 2-\mathrm{H} 1 \mathrm{~N} 1$ preimmune groups on day 14 postprime vaccination. HAl titers are given for each vaccine group 14 days after the first vaccination (Continued on next page) 
significantly higher mean titer than compared to the H1N1, H3N2, and H1N1-H3N2 group, which were not significantly different from each other. The H3N2-H1N1 preimmunity overall mean was not significantly different from the mock preimmunity mean titer.

Neutralization assays. Serum was collected from the ferrets after the second vaccination and pooled in equal amounts for the neutralization assay. The Mal/NL/01-, Mal/ WI/08-, and Z1-vaccinated ferrets with the H2N2 preimmunity all had neutralizing antibodies titers of $\geq 1: 350$ to 5 of the 7 influenza viruses in the neutralization panel (Table 2). The Z5-vaccinated ferrets had neutralizing antibodies titers of $\geq 1: 350$ to 6 of the 7 influenza viruses. The H3N2 preimmune ferret groups all had neutralization titers lower than 1:200 to all of the influenza viruses in panel except for Sw/MO/06, where the Mal/NL/01-, Mal/Wl/08-, Z1-, and Z5-vaccinated ferrets all had titers of $>1: 450$. In the $\mathrm{H} 1 \mathrm{~N} 1$ preimmune group, the Mal/NL/01 and Z5 vaccine groups had neutralization titers of $>1: 100$ to 2 of the 7 influenza viruses in the panel, while the Mal/WI/08 and Z1 vaccine groups had neutralization titers of $>1: 100$ for 4 and 5 of the influenza viruses, respectively. The Mal/NL/01- and Z5-vaccinated ferrets in the $\mathrm{H} 3 \mathrm{~N} 2-\mathrm{H} 1 \mathrm{~N} 1$ preimmune group had neutralization titers of $>1: 200$ to 2 of the 7 influenza viruses in the $\mathrm{H} 2 \mathrm{Nx}$ virus panel. The Mal/WI/08-vaccinated ferrets had neutralization titers of $>1: 200$ only to the Sw/MO/06 H2N3 influenza virus. The Z1-vaccinated ferrets had titers of $>200$ to 5 of the 7 influenza viruses. For the H1N1-H3N2 preimmune group, the Mal/NL/01-, Mal/ WI/08-, Z1-, and Z5-vaccinated ferrets all had neutralization titers of $>1: 150$ to 4 of the 7 influenza viruses. For the nonpreimmune group, the Mal/NL/01-, Mal/Wl/08-, Z1-, and $Z 5$-vaccinated ferrets all had neutralization titers of $>1: 350$ to the Sw/MO/06 influenza virus. The Z1-vaccinated ferrets had neutralization titers of $>1: 150$ to 3 of the 6 other influenza viruses in the panel, while the $Z 5$-vaccinated ferrets had neutralization titers of $>1: 150$ to one other influenza virus in the panel.

\section{DISCUSSION}

Currently, the United States stockpiles prepandemic influenza virus vaccines for both $\mathrm{H} 5$ and $\mathrm{H} 7$ influenza subtypes (30). While both $\mathrm{H} 5$ and $\mathrm{H} 7$ influenza viruses have infected humans, there has been little human-to-human transmission of these influenza virus subtypes. Conversely, H2N2 influenza viruses caused the 1957 influenza pandemic (3). It is likely that $\mathrm{H} 2$ influenza viruses may cause future pandemics and, therefore, next-generation, broadly reactive universal influenza vaccines should elicit protective immune responses against current and future $\mathrm{H} 2$ influenza viruses. Currently, humans develop long-lasting memory cells against seasonal influenza $A$ and $B$ viruses following infection and/or vaccination. However, few studies have investigated the effects of vaccinating individuals for a novel subtype of influenza virus in the presence of preexisting immunity to historical influenza strains. This study addressed the effectiveness of vaccinating ferrets that have preexisting immunity induced by historical influenza A virus (IAV) strains with both WT and COBRA H2 rHA vaccines to stimulate protective immune responses.

IAV naive ferrets were infected individually with $\mathrm{H} 1 \mathrm{~N} 1, \mathrm{H} 2 \mathrm{~N} 2$, or H3N2 influenza viruses prior to $\mathrm{H} 2$ rHA vaccination. Some ferrets were also infected sequentially with $\mathrm{H} 1 \mathrm{~N} 1$ and H3N2 influenza viruses. Following a single vaccination of the COBRA HA vaccines, ferrets preimmune to group 1 influenza $A$ viruses all had broadly cross-reactive antibodies. This included the ferrets that were administered the H1N1 virus prior to the $\mathrm{H} 3 \mathrm{~N} 2$ virus. Ferrets infected with H3N2 influenza viruses initially had no cross-reactive $\mathrm{HAl}$ titers to $\mathrm{H} 2$ influenza viruses after the first vaccination, which was similar to naive

FIG 7 Legend (Continued)

(day 14 ) in the $\mathrm{H} 1 \mathrm{~N} 1-\mathrm{H} 3 \mathrm{~N} 2$ preimmunity (A to $E$ ) and $\mathrm{H} 3 \mathrm{~N} 2-\mathrm{H} 1 \mathrm{~N} 1$ preimmunity ( $F$ to $J$ ) groups. Dotted lines indicate 1:40 and 1:80 HAI titers, respectively. The VLP panel is composed of: clade-1 HAs (Mallard/Netherlands/2001, Chicken/Potsdam/1984, Muskrat/Russia/2014, and Duck/Cambodia/ 2013), clade-2 HAs (Duck/Hong Kong/1978, Taiwan/1/1964, Moscow/1019/1965, and Japan/305/1957), and clade-3 HAs (Mallard/Wisconsin/2008, Swine/Missouri/2006, Quail/Rhode Island/2016, and Turkey/ California/2008). Error bars represent standard mean errors. 

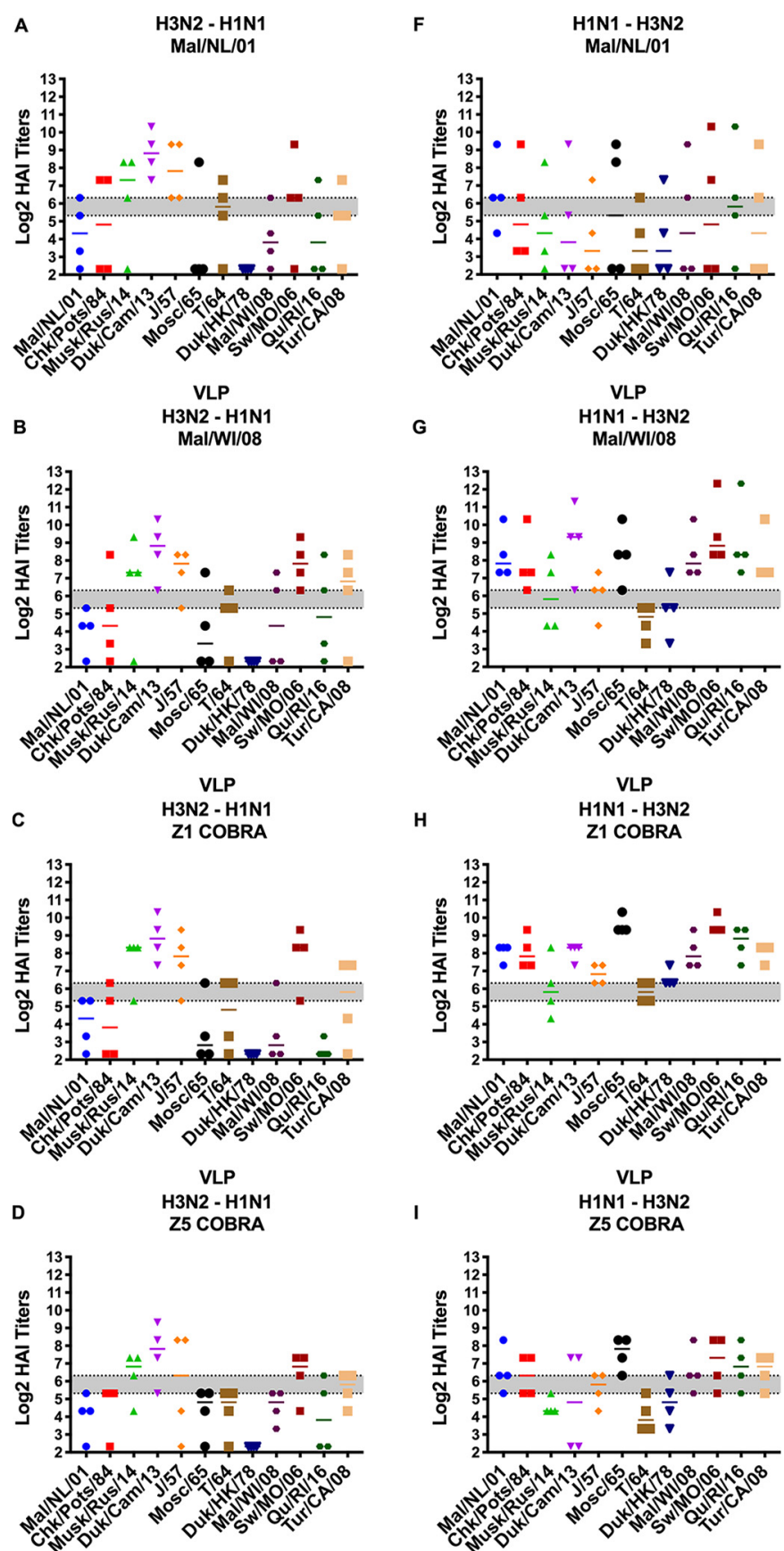

VLP
H1N1 - H3N2
75 COBRA

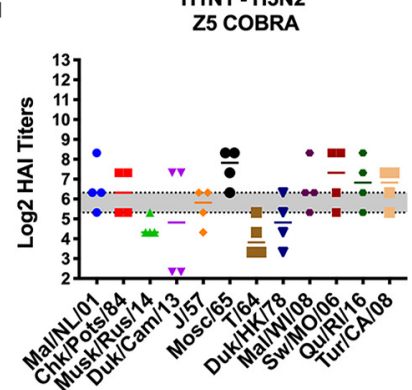

VLP

E

H3N2 - H1N

Mock

J

VLP
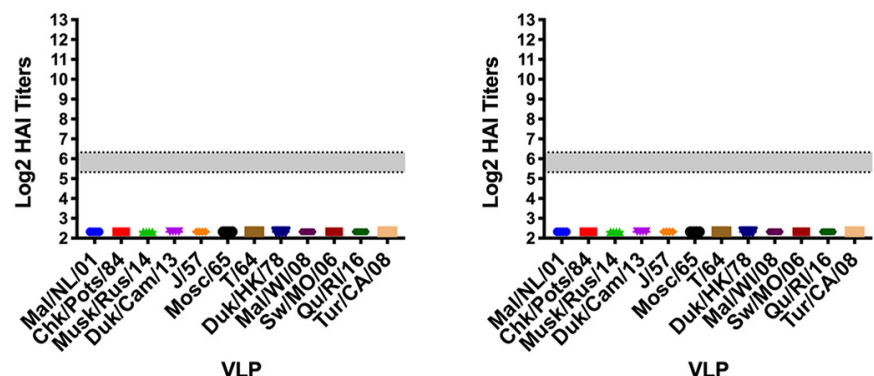

FIG 8 Antibody cross-reactivity of H1N1-H3N2 and H3N2-H1N1 preimmune groups on day 42 postprime (day 14 post-boost) vaccination. HAl titers are given for each vaccine group 14 days after the (Continued on next page) 
TABLE 2 Ferret neutralization titers on day 42 post-prime sera (day 14 post-boost) ${ }^{a}$

\begin{tabular}{|c|c|c|c|c|c|c|c|c|c|}
\hline Preimmunity & Vaccine & Significance group & Chk/pots/84 & Chk/PA/04 & For/57 & $\mathrm{T} / 64$ & Duk/HK/78 & Sw/MO/06 & Mall/MN/08 \\
\hline $\mathrm{H} 2 \mathrm{~N} 2$ & $\mathrm{Mal} / \mathrm{NL} / 01$ & $\mathrm{a}$ & 640 & 380 & 48 & 34 & 640 & 640 & 452 \\
\hline $\mathrm{H} 2 \mathrm{~N} 2$ & $\mathrm{Mal} / \mathrm{Wl} / 08$ & a & 640 & 537 & 48 & 56 & 640 & 640 & 640 \\
\hline $\mathrm{H} 2 \mathrm{~N} 2$ & $\mathrm{Z1}$ & a & 640 & 640 & 134 & 67 & 640 & 640 & 640 \\
\hline $\mathrm{H} 2 \mathrm{~N} 2$ & Mock & b & 95 & 156 & 8 & 24 & 48 & 537 & 95 \\
\hline $\mathrm{H} 3 \mathrm{~N} 2$ & $\mathrm{Mal} / \mathrm{NL} / 01$ & $b$ & 17 & 7 & 5 & 20 & 12 & 452 & 17 \\
\hline $\mathrm{H} 3 \mathrm{~N} 2$ & $\mathrm{Mal} / \mathrm{Wl} / 08$ & $a b$ & 48 & 67 & 5 & 28 & 24 & 640 & 67 \\
\hline $\mathrm{H} 3 \mathrm{~N} 2$ & Mock & c & 5 & 7 & 5 & 5 & 5 & 6 & 6 \\
\hline $\mathrm{H} 1 \mathrm{~N} 1$ & $\mathrm{Mal} / \mathrm{NL} / 01$ & $\mathrm{~b}$ & 113 & 20 & 5 & 95 & 28 & 537 & 24 \\
\hline $\mathrm{H} 1 \mathrm{~N} 1$ & $\mathrm{Mal} / \mathrm{Wl} / 08$ & $a b$ & 113 & 40 & 6 & 537 & 34 & 640 & 226 \\
\hline H1N1 & $\mathrm{Z1}$ & $\mathrm{a}$ & 537 & 269 & 20 & 80 & 269 & 640 & 269 \\
\hline $\mathrm{H} 1 \mathrm{~N} 1$ & $\mathrm{Z5}$ & $a b$ & 134 & 48 & 10 & 20 & 80 & 640 & 12 \\
\hline $\mathrm{H} 1 \mathrm{~N} 1$ & Mock & c & 8 & 6 & 5 & 5 & 5 & 5 & 5 \\
\hline $\mathrm{H} 3 \mathrm{~N} 2, \mathrm{H} 1 \mathrm{~N} 1$ & Mock & $b$ & 5 & 5 & 7 & 5 & 5 & 6 & 6 \\
\hline H1N1, H3N2 & Mal/NL/01 & a & 640 & 640 & 34 & 5 & 80 & 640 & 640 \\
\hline H1N1, H3N2 & $\mathrm{Mal} / \mathrm{Wl} / 08$ & a & 537 & 269 & 40 & 40 & 80 & 640 & 380 \\
\hline $\mathrm{H} 1 \mathrm{~N} 1, \mathrm{H} 3 \mathrm{~N} 2$ & $\mathrm{Z1}$ & a & 226 & 640 & 67 & 113 & 95 & 640 & 537 \\
\hline $\mathrm{H} 1 \mathrm{~N} 1, \mathrm{H} 3 \mathrm{~N} 2$ & $\mathrm{Z5}$ & a & 269 & 269 & 20 & 40 & 113 & 640 & 190 \\
\hline $\mathrm{H} 1 \mathrm{~N} 1, \mathrm{H} 3 \mathrm{~N} 2$ & Mock & $b$ & 5 & 6 & 5 & 5 & 5 & 5 & 5 \\
\hline Mock & Mal/NL/01 & $\mathrm{b}$ & 34 & 14 & 5 & 10 & 10 & 640 & 20 \\
\hline Mock & $\mathrm{Mal} / \mathrm{Wl} / 08$ & $a b$ & 12 & 17 & 5 & 5 & 7 & 640 & 20 \\
\hline Mock & $\mathrm{Z1}$ & c & 537 & 190 & 40 & 80 & 226 & 640 & 80 \\
\hline Mock & $\mathrm{Z5}$ & $b$ & 160 & 28 & 6 & 10 & 56 & 380 & 14 \\
\hline Mock & Mock & a & 5 & 5 & 5 & 5 & 5 & 5 & 5 \\
\hline
\end{tabular}

${ }^{a}$ Neutralization titers were obtained from pooled sera. Titers were obtained by taking the geometric mean titer of the replicates for each of the vaccine groups. Each column is a virus that was used in the neutralization assay. Each row is the sera from a vaccination group. The lower limit of detection is 5 , while the upper limit of detection is 640 . Significance group is determined for each individual preimmunity group. Within one preimmune group, the vaccines' ability to elicit neutralization titers were compared while controlling for the main effects of virus used in the assay. Vaccination groups within a preimmunity that share a lowercase letter were not significantly different from one another.

ferrets. This result shows that the first subtype of influenza virus that a person is infected with affects their future immune responses to subsequent heterotypic influenza virus vaccinations. This phenomenon, termed "immune imprinting," has been well-documented for IAV (26-28). These previous studies showed how the IAV that an individual was first infected with seemed to confer protection to other influenza virus subtypes within the same HA evolutionary group. Group 1 influenza virus HA subtypes include $H 1, H 2, H 5$, and $H 9$, while group 2 influenza virus $H A$ subtypes include $H 3$ and $\mathrm{H} 7(27,28)$. In this study, the broader HAl activity after the prime vaccination in the H1N1 preimmune ferrets compared to the H3N2 preimmune ferrets further support the IAV group-specific immune imprinting theory.

De novo immune responses appear more important and are required for the H3N2 (group 2) imprinted ferrets to generate cross-reactive antibodies to $\mathrm{H} 2$ influenza viruses than is the case for the H1N1 or H2N2 (group 1) preimmune ferrets. Once the animals were administered a second vaccination, the H3N2 and H3N2-H1N1 preimmune groups had detectable HAl titers, but the titers were 2- to 4-fold lower on average than group 1-imprinted ferrets. The group 2-imprinted ferrets likely have B cells

FIG 8 Legend (Continued)

second vaccination (day 42) in the H1N1-H3N2 preimmunity (A to E) H3N2-H1N1 preimmunity ( $F$ to J) groups. Dotted lines indicate 1:40 and 1:80 HAl titers, respectively. The VLP panel is composed of: clade-1 HAs (Mallard/Netherlands/2001, Chicken/Potsdam/1984, Muskrat/Russia/2014, and Duck/ Cambodia/2013), clade-2 HAs (Duck/Hong Kong/1978, Taiwan/1/1964, Moscow/1019/1965, and Japan/ 305/1957), and clade-3 HAs (Mallard/Wisconsin/2008, Swine/Missouri/2006, Quail/Rhode Island/2016, and Turkey/California/2008). Error bars represent standard mean errors. 
that are highly specific to epitopes on the H3 HA (31). These epitopes are far less similar to the epitopes on $\mathrm{H} 2 \mathrm{HA}$ than the epitopes on $\mathrm{H} 1 \mathrm{HA}$. Without any similar immune memory, the H3N2 influenza virus-imprinted ferrets would likely need to generate de novo B cells to the COBRA H2 HA vaccine (27). Meanwhile, the H1N1 influenza virusimprinted ferrets have memory $B$ cells that may recognize similar epitopes on the $\mathrm{H} 2$ HA proteins. These memory B cells would undergo somatic hypermutation and adapt to the H2 HA epitopes (32). Therefore, sequential infections of influenza viruses may affect the immune responses to future influenza virus infections or vaccinations (27, $28,31,32$ ) Since most people under 55 years old will have preexisting memory cells to both $\mathrm{H} 1 \mathrm{~N} 1$ and $\mathrm{H} 3 \mathrm{~N} 2$ influenza viruses, a stockpiled $\mathrm{H} 2$ influenza virus vaccine will likely need a prime and boost vaccination in order to generate de novo immune responses to adequately protect the majority of individuals from a future $\mathrm{H} 2$ influenza virus infections.

Mortality in the mock-vaccinated ferrets was absent in all of the preimmune groups with the exception of the naive preimmune ferrets following the H2N3 virus challenge. This result was surprising, since none of the mock-vaccinated ferrets in any of the preimmune groups (with the exception of the H2N2 preimmune ferrets) had substantial $\mathrm{HAl}$ or neutralization titers to any of the H2 VLPs or influenza viruses tested in these assays. Given these results, it is likely that other immune mechanisms may be playing a role in protecting ferrets from mortality during the viral challenge. Without $\mathrm{H} 2$-specific neutralizing antibodies, it is possible that either nonneutralizing antibodies or $\mathrm{T}$ cells are contributing to protection against the Sw/MO/06 H2N3 virus infection (33-36). Nonneutralizing antibodies could be contributing to protection through antibody-dependent cellular cytotoxicity (ADCC) or complement-dependent cytotoxicity (37-39). Both $\mathrm{CD}^{+}$and $\mathrm{CD}^{+} \mathrm{T}$ cells are elicited following infection and they are effective against secondary influenza virus infections $(40,41)$. There may be epitopes on the HA that could elicit broadly cross-reacting $T$ cells that help clear virally infected cells $(42,43)$. In addition, influenza virus-elicited $\mathrm{T}$ cells responsive to internal gene products, such as nucleoprotein (NP) of both the H1N1 and H3N2 viruses, could recognize epitopes on the internal genes of the Sw/MO/06 challenge virus. Further studies are needed to identify the exact mechanism of protection in these preimmune animal models.

Across all of the preimmune groups, the Z1-vaccinated ferrets had significantly higher cross-reactive $\mathrm{H} 2$ antibody titers compared to the other vaccination groups. The Z1-vaccinated ferrets had the highest average HAl titers and recognized more $\mathrm{H} 2$ strains than the other vaccines across all of the different preimmunities. The Z1vaccinated ferrets also had the highest average neutralization titers to more $\mathrm{H} 2$ influenza viruses regardless of the preimmune background. The COBRA H2 HA vaccine is likely outperforming the wild-type $\mathrm{H} 2 \mathrm{HA}$ vaccines because they have more diverse epitopes. Higher diversity of epitopes in the COBRA HA would more likely elicit B cells that cross-react across different antigenic sites on the H2 HA. Higher diversity of epitopes is beneficial for vaccinating people who are all preimmune to either $\mathrm{H} 1 \mathrm{~N} 1$ and/or H3N2 influenza viruses. Vaccinating with a COBRA H2 HA antigen with highly diverse cross-reactive epitopes on a single antigen would increase the likelihood that multiple cross-reactive $B$ cells will be retained in long-term immunological memory.

The Z1 COBRA HA also outperformed the Z5 COBRA and the two wild-type vaccines. Z1 outperforming Z5 was somewhat surprising, since there are only four amino acids that differ between the two HA sequences. However, these four amino acids are spread across three of the seven antigenic sites on the H2 HA molecule $(44,45)$. It is likely that these mutations are altering the structure of multiple epitopes that are recognized by $B$ cells and resulting in decreased antibody cross-reactive binding to other $\mathrm{H} 2 \mathrm{HA}$ proteins. Therefore, the Z1 COBRA HA would be an ideal vaccine candidate for a future stockpiled $\mathrm{H} 2$ influenza virus vaccine to be administered to protect people from a future $\mathrm{H} 2$ influenza virus pandemic. 


\section{MATERIALS AND METHODS}

Viruses, recombinant HA proteins, and virus-like particles. A/Chicken/Potsdam/4705/1984 (Chk/ Pots/84) (H2N2) (clade-1), A/Chicken/PA/298101-4/2004 (Chk/PA/04) (H2N2) (clade-1), A/Duck/Hong Kong/273/1978 (Duk/HK/78) (H2N2) (clade-2), A/Mallard/Minnesota/Al08-3437/2008 (Mal/MN/08) (H2N3) (clade-3), A/Swine/Missouri/4296424/2006 (Sw/MO/06) (H2N3) (clade-3), A/Formosa/313/1957 (For/57) (H2N2) (clade-2), and A/Taiwan/1/1964 (T/64) (H2N2) (clade-2) were obtained from either the United States Department of Agriculture (USDA) Diagnostic Virology Laboratory (DVL) in Ames, lowa, from BEI resources (Manassas, VA, USA), or provided by the laboratory of S. Mark Tompkins (Athens, GA, USA). Each influenza virus was passaged using embryonated chicken eggs except for the Sw/MO/06 virus, which was passaged in MDCK cells. Each influenza virus was harvested from either the eggs or cells and aliquoted into tubes which were stored at $-80^{\circ} \mathrm{C}$. Each influenza virus was titered using a standard influenza plaque assay as described below.

Recombinant HA (rHA) proteins were expressed using the pcDNA 3.1+ plasmid (Addgene, Watertown, MA). Each HA gene was truncated by removing the transmembrane (TM) domain and the cytoplasmic tail at the $3^{\prime}$ end of the gene (amino acids 527 to 562). The TM domain was determined using the TMHMM Server v. 2.0 website: http://www.cbs.dtu.dk/services/TMHMM/. The HA gene was truncated at the first amino acid prior to the TM domain. A fold-on domain from T4 bacteriophage (46), an Avitag (47), and a $6 \times$ histidine tag totaling 477 nucleotides were added to the $3^{\prime}$ end of the HA gene. The pcDNA 3.1+ vectors were then transfected individually into human embryonic kidney (HEK293T) suspension cells using ExpiFectamine 293 transfection reagent (Thermo Fisher Scientific, Waltham, MA, USA) following the manufacturer's specifications. The supernatants $(\sim 500 \mathrm{ml})$ were then harvested from the transfected HEK293T cells. Each rHA was then purified from the supernatant using a nickel-agarose column (Thermo Fisher Scientific, Waltham, MA, USA). The rHA proteins were then eluted from the column using $100 \mathrm{mM}$ imidazole (Thermo Fisher Scientific, Waltham, MA, USA). After elution, the proteins were quantified using bicinchoninic assay (BCA) (Thermo Fisher Scientific, Waltham, MA, USA) and stored at $-80^{\circ} \mathrm{C}$. Recombinant $\mathrm{HA}$ proteins produced for this study were A/Mallard/Netherlands/13/2001 (Mal/ NL/01), Mallard/Wisconsin/08OS2844/2008 (Mal/Wl/08), Z1 COBRA (Z1), and Z5 COBRA (Z5).

For the virus-like particle (VLP) production, adherent human endothelial kidney 293T (HEK-293T) cells were grown in complete Dulbecco's modified eagles' medium (DMEM). Once confluent $\left(1 \times 10^{6}\right)$, these cells were transiently transfected for the creation of mammalian virus-like particles (VLPs). Viral proteins were expressed from the pTR600 mammalian expression vectors (48). Influenza virus neuraminidase (A/South Carolina/1/1918; H1N1), the HIV p55 Gag, and HA expression plasmids expressing one of the $\mathrm{H} 2$ wild-type or $\mathrm{H} 2$ COBRA HA proteins were added to serum-free medium following the Lipofectamine 3000 protocol in a 1:2:1 ratio with a final DNA concentration of $1 \mu \mathrm{g}$. Following $72 \mathrm{~h}$ of incubation at $37^{\circ} \mathrm{C}$, supernatants from transiently transfected cells were collected, centrifuged to remove cellular debris, and filtered through a $0.22-\mu \mathrm{m}$ pore membrane. VLPs were purified and sedimented by ultracentrifugation on a $20 \%$ glycerol cushion at $23,500 \times g$ for $4 \mathrm{~h}$ at $4^{\circ} \mathrm{C}$. VLPs were resuspended in phosphate-buffered saline (PBS) and the total protein concentration was determined with the Micro BCA protein assay reagent kit (Pierce Biotechnology, Rockford, IL, USA). Hemagglutination activity of each preparation of VLP was determined by serially diluting volumes of VLPs and adding an equal volume of $0.8 \%$ turkey red blood cells (RBCs) (Lampire Biologicals, Pipersville, PA, USA) suspended in PBS to a V-bottom 96-well plate with a $30 \mathrm{~min}$ incubation at room temperature (RT). Prepared RBCs were stored at $4^{\circ} \mathrm{C}$ and used within $72 \mathrm{~h}$. The highest dilution of VLP with full agglutination of RBCs was considered the endpoint HA titer. The H2 HA sequences used for VLPs were Mal/NL/01, Chk/Pots/84, Muskrat/ Russia/63/2014 (Musk/Rus/14) (clade-1), Duck/Cambodia/419W12M3/2013 (Duk/Cam/13) (clade-2), Japan/305/1957 (J/57) (clade-2), Moscow/1019/1965 (Mosc/65) (clade-2), T/64, Duk/HK/78, Mal/WI/08, Sw/MO/06, Quail/Rhode Island/16-018622-1/2016 (Qu/RI/16) (clade-3), and Turkey/California/1797/2008 (TK/CA/08) (clade-3).

Ferret vaccination and challenge experiments. Fitch ferrets (Mustela putorius furo, spayed, female, 6 to 12 months of age) were purchased certified influenza-free and descented from Triple F Farms (Sayre, PA, USA). Ferrets were pair housed in stainless steel cages (Shor-Line, Kansas City, KS) containing Sani-Chips laboratory animal bedding (P. J. Murphy Forest Products, Montville, NJ). Ferrets were provided with Teklad Global Ferret Diet (Harlan Teklad, Madison, WI) and fresh water ad libitum. The University of Georgia Institutional Animal Care and Use Committee approved all experiments, which were conducted in accordance with the National Research Council's Guide for the Care and Use of Laboratory Animals, the Animal Welfare Act, and the CDC/NIH's Biosafety in Microbiological and Biomedical Laboratories guide. Ferrets $(n=20)$ were preinfected with H1N1, or H3N2 seasonal influenza viruses or $\mathrm{H} 2 \mathrm{~N} 2$ avian influenza viruses in different orders before vaccination. These influenza viruses included the H1N1 influenza viruses Singapore/6/1986 (Sing/86) and California/07/2009 (CA/09), the H3N2 influenza viruses Sichuan/2/1987 (Sich/87) or Panama/2007/1999 (Pan/99), and the H2N2 avian influenza viruses Chk/PA/04 or Qu/RI/16, all at an infectious dose of $1 \mathrm{e}+6 \mathrm{PFU}$ in $1 \mathrm{ml}$ intranasally. For the ferrets with multiple preimmune infections, ferrets were left for 60 days between each infection and before the first vaccination.

After the establishment of preimmunity by viral infection, 60 days elapsed before ferrets were vaccinated with recombinant hemagglutinin ( $\mathrm{rHA}$ ) twice with 4 weeks between vaccinations. The ferrets were vaccinated with a 1:1 ratio $(500 \mu \mathrm{l}$ total volume) of rHA diluted with phosphate-buffered saline (PBS) $(15.0 \mu \mathrm{g} \mathrm{rHA} /$ ferret) and the emulsified oil-water adjuvant Addavax (InvivoGen, San Diego, CA, USA). The mock-vaccinated groups received only PBS and Addavax adjuvant at a 1:1 ratio $(500 \mu$ l total volume) with no rHA. Each vaccination was given intramuscularly. Before vaccinations and 2 weeks after each of the vaccinations, ferrets were bled and serum was isolated from each of the samples. The blood 
was harvested from all anesthetized ferrets via the anterior vena cava at days 0,14 , and 42 . Blood samples were incubated at room temperature for $1 \mathrm{~h}$ prior to centrifugation at $6,000 \mathrm{rpm}$ for $10 \mathrm{~min}$. The separated serum was removed and frozen at $-20^{\circ} \mathrm{C}$. The ferrets were infected 4 to 6 weeks after the second vaccination with the H2N3 influenza virus Swine/Missouri/4296424/2006 (Sw/MO/06). Animals were monitored daily for 10 days postinfection for clinical symptoms such as weight loss $(20 \% n=3)$, lethargy $(n=1)$, sneezing, dyspnea $(n=2)$, and neurological symptoms $(n=3)$. Any ferret that reached a cumulative score $(n)$ of three was euthanized per rules set by The University of Georgia Institutional Animal Care and Use Committee. In this study, every ferret that reached humane endpoints exhibited both lethargy $(n=1)$ and dyspnea $(n=2)$ (total score of $n=3)$.

Hemagglutination inhibition assay. The hemagglutination inhibition (HAI) assay was used to quantify HA-specific antibodies by measuring the inhibition in the agglutination of turkey erythrocytes. The protocol was adapted from the WHO laboratory of influenza surveillance manual (49). To inactivate nonspecific inhibitors, the serum was treated with receptor-destroying enzyme (RDE) (Denka Seiken, Co., Japan) prior to being tested. Briefly, three parts RDE were added to one-part serum and incubated overnight at $37^{\circ} \mathrm{C}$. RDE was inactivated by incubating at $56^{\circ} \mathrm{C}$ for approximately $45 \mathrm{~min}$. After the incubation period, six parts PBS were added to the RDE-treated serum. RDE-treated sera were 2-fold serially diluted in V-bottom microtiter plates. An equal volume of each virus-like particle (VLP) was adjusted to approximately 8 hemagglutination units ( $\mathrm{HAU}) / 25 \mu \mathrm{l}$ and was added to each well. The plates were covered and incubated at RT for 20 min before $50 \mu$ l of RBCs were allowed to settle for 30 min at RT.

The HAl titer was determined by the reciprocal dilution of the last well that contained nonagglutinated RBCs. Positive and negative serum controls were included on each plate. Seroprotection was defined as an HAl titer of $\geq 1: 40$ and seroconversion as a 4-fold increase in titer compared to baseline, as defined by the WHO to evaluate influenza vaccines (49).

Determination of viral nasal wash titers. The nasal washes were performed on anesthetized ferrets by washing out each of their nostrils with a total of $3 \mathrm{ml}$ of PBS on days 1, 3, 5, and 7 postinfection. From each nasal wash, $\sim 2.0 \mathrm{ml}$ was recovered. The nasal washes were aliquoted into microcentrifuge tubes and stored at $-80^{\circ} \mathrm{C}$. Nasal wash aliquots were thawed at RT. Once thawed, 10-fold serial dilutions of nasal washes were overlaid on MDCK cells (49). The MDCK cells were at 95 to $100 \%$ confluence at the time that the assay was performed. Nasal wash samples were incubated for $60 \mathrm{~min}$ at RT with agitation every $15 \mathrm{~min}$. After $60 \mathrm{~min}$, the serial dilutions were removed and the MDCK cells were washed with incomplete (no fetal bovine serum [FBS]) DMEM containing penicillin and streptomycin (P/S). The wash medium was removed and replaced with $1 \mathrm{ml}$ of a mixture of plaque medium without FBS, TPCK-trypsin, and $1.2 \%$ avicel. Plaque medium was made using MEM medium, HEPES buffer, L-glutamine, and P/S. All of the components of the plaque medium and avicel were obtained from Thermo Fisher Scientific (Waltham, MA, USA). The MDCK cells were incubated at $37^{\circ} \mathrm{C}$ with $5 \% \mathrm{CO}_{2}$ for $48 \mathrm{~h}$. After $48 \mathrm{~h}$, the avicel overlay was removed and the MDCK cells were fixed with $10 \%$ buffered formalin for a minimum of $15 \mathrm{~min}$. The formalin was then discarded, and the MDCK cells were stained using $1 \%$ crystal violet. The MDCK cells were then washed with distilled water to remove the crystal violet. Plaques were then counted and PFU per ml titer was calculated using the number of plaques and the appropriate dilution factor.

Neutralization assays. The neutralization assay was used to identify the presence of virus-specific neutralizing antibodies. The protocol was adapted from the WHO laboratory of influenza surveillance manual (49). Equal amounts of serum from each ferret within a vaccination group were combined and heat-inactivated for $30 \mathrm{~min}$ at $56^{\circ} \mathrm{C}$. MDCK cells were grown in a 96-well flat-bottom plate until they reached 95 to $100 \%$ confluence. Antibodies were diluted in half-log increments with serum-free medium and incubated with $100 \times 50 \%$ tissue culture infective dose $\left(T_{C I D}\right)$ for $1 \mathrm{~h}$. The antibody-virus mixture was then added to the incomplete (FBS-free) DMEM-washed MDCK cells in the 96-well plate. After $2 \mathrm{~h}$, the MDCK cells were washed with incomplete DMEM. Approximately $200 \mu \mathrm{l}$ of DMEM with P/S and $2.0 \mu \mathrm{g} / \mathrm{ml}$ of TPCK were added to each of the 96 wells. The cell monolayers in the back-titration control wells were checked daily until cytopathic effect (CPE) had reached the majority of the $1 \times \mathrm{TCID}_{50}$ rows. After 3 or 4 days, $50 \mu \mathrm{l}$ of medium per well was removed and used in an HA assay to identify the presence of influenza virus. The remaining medium in each well was removed and the MDCK cells were then fixed with $10 \%$ buffered formalin for a minimum of $15 \mathrm{~min}$. The formalin was then discarded and the fixed cells were washed with $1 \times$ PBS. Afterward, the MDCK cells were stained using $1 \%$ crystal violet (Thermo Fisher Scientific, Waltham, MA, USA). The MDCK cells were then washed with distilled water to remove the crystal violet. Any well having an HA activity of $\geq 1: 2$ was defined as positive for the analysis. HA activity was confirmed by $>10 \%$ of CPE in wells that was positive for HA activity.

Statistical analysis. Statistical significance was defined as a $P$ value of less than 0.05 . The limit of detection for viral plaque titers was $50 \mathrm{PFU} / \mathrm{ml}$ for statistical analysis. The viral plaque titers were transformed by $\log _{10}$ for analysis. The limit of detection for HAI was $<1: 10$ and 1:5 was used for statistical analysis. The HAI titers were transformed by $\log _{2}$ for analysis and graphing. The geometric mean titers were calculated for neutralization assays, but the $\log _{2}$ titers were used for ANOVA analysis. All error bars on the graphs represent standard mean error. ANOVAs with Dunnet's test were used for weight loss, with a statistical significance defined as a $P$ value of less than 0.05 . Nasal wash titers stratified by day and preimmunity were analyzed with a one-way ANOVA with the Tukey's honestly significant difference method to determine differences between vaccine groups. The overall performance of the vaccines was assessed through multivariate ANOVAs for main effects conducted individually for the neutralization titer, viral nasal wash titer, and HAl titer outcomes, followed by Tukey's honestly significant difference method for adjusting for multiple comparisons. Significantly 
different groups per outcome were determined from the multiple comparisons. Day 7 of the nasal wash titer was not included in the ANOVA analysis since all of the observations were below the limit of detection. All of the statistical analysis for the various assays can be found in Fig. S2, Fig. S5, and Table S1 in the supplemental material.

Amino acid sequences. The amino acid sequences for the two COBRA HA sequences have been reported in the United States provisional patent filing 14332088_1.

\author{
SUPPLEMENTAL MATERIAL \\ Supplemental material is available online only. \\ FIG S1, TIF file, 0.3 MB. \\ FIG S2, TIF file, 0.5 MB. \\ FIG S3, TIF file, 0.5 MB. \\ FIG S4, TIF file, 0.8 MB. \\ FIG S5, TIF file, 0.8 MB. \\ FIG S6, TIF file, $0.9 \mathrm{MB}$. \\ FIG S7, TIF file, 0.7 MB. \\ TABLE S1, TIF file, $0.3 \mathrm{MB}$.
}

\title{
ACKNOWLEDGMENTS
}

We thank Ivette A Nunez, Ying Huang, James D. Allen, and Hyesun Jang for technical assistance. We thank the CVI protein production core for providing technical assistance in purifying recombinant HA proteins, as well as the University of Georgia Animal Resource staff, technicians, and veterinarians for excellent animal care.

Z.B.R., conceptualization, formal analysis, methodology, writing; A.L.S., formal analysis, writing; P.J.J., formal analysis, writing; T.M.R., conceptualization, formal analysis, funding acquisition, methodology, writing.

T.M.R. has a patent on the COBRA methodology.

This work was funded in part by the University of Georgia (UGA) (MRA-001). In addition, T.M.R. is supported by the Georgia Research Alliance as an Eminent Scholar.

\section{REFERENCES}

1. Centers for Disease Control and Prevention. 2019. 1957-1958 Pandemic (H2N2 virus). Centers for Disease Control and Prevention, Atlanta, GA. https://www.cdc.gov/flu/pandemic-resources/1957-1958-pandemic.html.

2. Lindstrom SE, Cox NJ, Klimov A. 2004. Genetic analysis of human H2N2 and early H3N2 influenza viruses, 1957-1972: evidence for genetic divergence and multiple reassortment events. Virology 328:101-119. https:// doi.org/10.1016/j.virol.2004.06.009.

3. Knipe DM, Howley PM (ed). 2013. Fields virology, 6th ed. Lippincott Williams \& Wilkins, Philadelphia, PA.

4. The College of Physicians of Philadelphia. 2020. The history of vaccines. The College of Physicians of Philadelphia, Philadelphia, PA. Accessed 20 May 2020. https://www.historyofvaccines.org/timeline\#EVT_100808.

5. Krauss S, Obert CA, Franks J, Walker D, Jones K, Seiler P, Niles L, Pryor SP, Obenauer JC, Naeve CW, Widjaja L, Webby RJ, Webster RG. 2007. Influenza in migratory birds and evidence of limited intercontinental virus exchange. PLoS Pathog 3:e167. https://doi.org/10.1371/journal.ppat.0030167.

6. Kishida N, Sakoda Y, Shiromoto M, Bai GR, Isoda N, Takada A, Laver G, Kida H. 2008. H2N5 influenza virus isolates from terns in Australia: genetic reassortants between those of the Eurasian and American lineages. Virus Genes 37:16-21. https://doi.org/10.1007/s11262-008-0235-z.

7. Marche S, Houdart P, van den Berg T, Lambrecht B. 2015. Multiyear serological surveillance of notifiable influenza A viruses in Belgian poultry: a retrospective analysis. Avian Dis 59:543-547. https://doi.org/10.1637/ 11122-050615-ResNote.

8. Wu H, Peng X, Peng X, Cheng L, Wu N. 2016. Genetic and molecular characterization of a novel reassortant $\mathrm{H} 2 \mathrm{~N} 8$ subtype avian influenza virus isolated from a domestic duck in Zhejiang Province in China. Virus Genes 52:863-866. https://doi.org/10.1007/s11262-016-1368-0.

9. Piaggio AJ, Shriner SA, VanDalen KK, Franklin AB, Anderson TD, Kolokotronis SO. 2012. Molecular surveillance of low pathogenic avian influenza viruses in wild birds across the United States: inferences from the hemagglutinin gene. PLoS One 7:e50834. https://doi.org/10.1371/journal.pone.0050834.
10. Killian ML, Zhang Y, Panigrahy B, Trampel D, Yoon KJ. 2011. Identification and characterization of $\mathrm{H} 2 \mathrm{~N} 3$ avian influenza virus from backyard poultry and comparison with novel H2N3 swine influenza virus. Avian Dis 55:611-619. https://doi.org/10.1637/9749-040111-Reg.1.

11. Ma W, Vincent AL, Gramer MR, Brockwell CB, Lager KM, Janke BH, Gauger PC, Patnayak DP, Webby RJ, Richt JA. 2007. Identification of H2N3 influenza A viruses from swine in the United States. Proc Natl Acad Sci U S A 104:20949-20954. https://doi.org/10.1073/pnas.0710286104.

12. Pappas C, Yang H, Carney PJ, Pearce MB, Katz JM, Stevens J, Tumpey TM. 2015. Assessment of transmission, pathogenesis and adaptation of $\mathrm{H} 2$ subtype influenza viruses in ferrets. Virology 477:61-71. https://doi.org/ 10.1016/j.virol.2015.01.002.

13. Veits J, Weber S, Stech O, Breithaupt A, Graber M, Gohrbandt S, Bogs J, Hundt J, Teifke JP, Mettenleiter TC, Stech J. 2012. Avian influenza virus hemagglutinins $\mathrm{H} 2, \mathrm{H} 4, \mathrm{H} 8$, and $\mathrm{H} 14$ support a highly pathogenic phenotype. Proc Natl Acad Sci U S A 109:2579-2584. https://doi.org/10.1073/ pnas. 1109397109.

14. Giles BM, Ross TM. 2011. A computationally optimized broadly reactive antigen (COBRA) based H5N1 VLP vaccine elicits broadly reactive antibodies in mice and ferrets. JV 29:3043-3054. https://doi.org/10.1016/j vaccine.2011.01.100

15. Giles BM, Bissel SJ, DeAlmeida DR, Wiley CA, Ross TM. 2012. Antibody breadth and protective efficacy are increased by vaccination with computationally optimized hemagglutinin but not with polyvalent hemagglutinin-based $\mathrm{H} 5 \mathrm{~N} 1$ virus-like particle vaccines. Clin Vaccine Immunol 19:128-139. https://doi.org/10.1128/CVI.05533-11.

16. Giles BM, Crevar CJ, Carter DM, Bissel SJ, Schultz-Cherry S, Wiley CA, Ross TM. 2012. A computationally optimized hemagglutinin virus-like particle vaccine elicits broadly reactive antibodies that protect nonhuman primates from H5N1 infection. J Infect Dis 205:1562-1570. https://doi.org/10 .1093/infdis/jis232.

17. Crevar CJ, Carter DM, Lee KY, Ross TM. 2015. Cocktail of H5N1 COBRA HA vaccines elicit protective antibodies against $\mathrm{H} 5 \mathrm{~N} 1$ viruses from multiple 
clades. Hum Vaccin Immunother 11:572-583. https://doi.org/10.1080/ 21645515.2015.1012013.

18. Wong TM, Allen JD, Bebin-Blackwell A-G, Carter DM, Alefantis T, DiNapol J, Kleanthous H, Ross TM. 2017. Computationally optimized broadly reactive hemagglutinin elicits hemagglutination inhibition antibodies against a panel of H3N2 influenza virus cocirculating variants. J Virol 91:e0158117. https://doi.org/10.1128/JVI.01581-17.

19. Carter DM, Darby CA, Johnson SK, Carlock MA, Kirchenbaum GA, Allen JD, Vogel TU, Delagrave S, DiNapoli J, Kleanthous H. 2017. Elicitation of protective antibodies against a broad panel of $\mathrm{H} 1 \mathrm{~N} 1$ viruses in ferrets preimmune to historical H1N1 influenza viruses. J Virol 91:e01283-17. https:// doi.org/10.1128/JVI.01283-17.

20. Carter DM, Darby CA, Lefoley BC, Crevar CJ, Alefantis T, Oomen R, Anderson SF, Strugnell T, Cortés-Garcia G, Vogel TU, Parrington M, Kleanthous H, Ross TM. 2016. Design and characterization of a computationally optimized broadly reactive hemagglutinin vaccine for $\mathrm{H} 1 \mathrm{~N} 1$ influenza viruses. J Virol 90:4720-4734. https://doi.org/10.1128/JVI .03152-15.

21. Allen JD, Jang H, DiNapoli J, Kleanthous H, Ross TM. 2019. Elicitation of protective antibodies against 20 years of future $\mathrm{H} 3 \mathrm{~N} 2$ cocirculating influenza virus variants in ferrets preimmune to historical H3N2 influenza viruses. J Virol 93:e00946-18. https://doi.org/10.1128/JVI 00946-18.

22. Carter DM, Bloom CE, Nascimento EJ, Marques ET, Craigo JK, Cherry JL, Lipman DJ, Ross T. 2013. Sequential seasonal H1N1 influenza virus infections protect ferrets against novel $2009 \mathrm{H} 1 \mathrm{~N} 1$ influenza virus. J Virol 87:1400-1410. https://doi.org/10.1128/JVI.02257-12.

23. Kirchenbaum GA, Carter DM, Ross T. 2016. Sequential infection in ferrets with antigenically distinct seasonal H1N1 influenza viruses boosts hemagglutinin stalk-specific antibodies. J Virol 90:1116-1128. https://doi .org/10.1128/JVI.02372-15.

24. Kirchenbaum GA, Ross T. 2014. Eliciting broadly protective antibody responses against influenza. Curr Opin Immunol 28:71-76. https://doi .org/10.1016/j.coi.2014.02.005.

25. Reneer ZB, Jamieson PJ, Skarlupka AL, Huang Y, Ross TM. 2020. Computationally optimized broadly reactive $\mathrm{H} 2 \mathrm{HA}$ influenza vaccines elicited broadly cross-reactive antibodies and protected mice from viral challenges. J Virol 95:e01526-20. https://doi.org/10.1128/JVI.01526-20.

26. Li Y, Myers JL, Bostick DL, Sullivan CB, Madara J, Linderman SL, Liu Q, Carter DM, Wrammert J, Esposito S, Principi N, Plotkin JB, Ross TM, Ahmed R, Wilson PC, Hensley SE. 2013. Immune history shapes specificity of pandemic H1N1 influenza antibody responses. J Exp Med 210:1493-1500. https://doi.org/10 .1084/jem.20130212.

27. Gostic KM, Ambrose M, Worobey M, Lloyd-Smith JO. 2016. Potent protection against $\mathrm{H} 5 \mathrm{~N} 1$ and $\mathrm{H} 7 \mathrm{~N} 9$ influenza via childhood hemagglutinin imprinting Science 354:722-726. https://doi.org/10.1126/science.aag1322.

28. Gostic KM, Bridge R, Brady S, Viboud C, Worobey M, Lloyd-Smith JO. 2019. Childhood immune imprinting to influenza A shapes birth year-specific risk during seasonal $\mathrm{H} 1 \mathrm{~N} 1$ and $\mathrm{H} 3 \mathrm{~N} 2$ epidemics. PLoS Pathog 15 e1008109. https://doi.org/10.1371/journal.ppat.1008109.

29. Francis ME, McNeil M, Dawe NJ, Foley MK, King ML, Ross TM, Kelvin AA. 2019. Historical H1N1 influenza virus imprinting increases vaccine protection by influencing the activity and sustained production of antibodies elicited at vaccination in ferrets. Vaccines (Basel) 7:133. https://doi.org/10 3390/vaccines7040133.

30. BARDA. 2019. Medical countermeasures, on U.S. Department of Health and Human Services. https://medicalcountermeasures.gov. Accessed 20 May 2020.

31. Tesini BL, Kanagaiah $P$, Wang J, Hahn M, Halliley JL, Chaves FA, Nguyen PQT, Nogales A, DeDiego ML, Anderson CS, Ellebedy AH, Strohmeier S, Krammer F, Yang H, Bandyopadhyay S, Ahmed R, Treanor JJ, Martinez-Sobrido L, Golding H, Khurana S, Zand MS, Topham DJ, Sangster MY. 2019. Broad hemagglutinin-specific memory $B$ cell expansion by seasonal influenza virus infection reflects early-life imprinting and adaptation to the infecting virus. J Virol 93:e00169-19. https://doi.org/10.1128/JVl.00169-19.

32. Cortina-Ceballos B, Godoy-Lozano EE, Tellez-Sosa J, Ovilla-Munoz M, Samano-Sanchez H, Aguilar-Salgado A, Gomez-Barreto RE, ValdovinosTorres H, Lopez-Martinez I, Aparicio-Antonio R, Rodriguez MH, MartinezBarnetche J. 2015. Longitudinal analysis of the peripheral B cell repertoire reveals unique effects of immunization with a new influenza virus strain. Genome Med 7:124. https://doi.org/10.1186/s13073-015-0239-y.
33. Henry Dunand CJ, Leon PE, Huang M, Choi A, Chromikova V, Ho IY, Tan GS, Cruz J, Hirsh A, Zheng NY, Mullarkey CE, Ennis FA, Terajima M, Treanor JJ, Topham DJ, Subbarao K, Palese P, Krammer F, Wilson PC. 2016. Both neutralizing and non-neutralizing human H7N9 influenza vaccineinduced monoclonal antibodies confer protection. Cell Host Microbe 19:800-813. https://doi.org/10.1016/j.chom.2016.05.014.

34. Tan GS, Leon PE, Albrecht RA, Margine I, Hirsh A, Bahl J, Krammer F. 2016 Broadly-reactive neutralizing and non-neutralizing antibodies directed against the $\mathrm{H} 7$ influenza virus hemagglutinin reveal divergent mechanisms of protection. PLoS Pathog 12:e1005578. https://doi.org/10.1371/ journal.ppat.1005578.

35. Hayward AC, Wang L, Goonetilleke N, Fragaszy EB, Bermingham A, Copas A, Dukes O, Millett ER, Nazareth I, Nguyen-Van-Tam JS, Watson JM, Zambon M, Johnson AM, McMichael AJ, Flu Watch Group. 2015. Natural T cell-mediated protection against seasonal and pandemic influenza. Results of the Flu Watch Cohort Study. Am J Respir Crit Care Med 191:1422-1431. https://doi.org/10.1164/rccm.201411-19880C.

36. Trieu MC, Zhou F, Lartey SL, Sridhar S, Mjaaland S, Cox RJ. 2018. Augmented CD4(+) T-cell and humoral responses after repeated annual influenza vaccination with the same vaccine component A/H1N1pdm09 over 5 years. NPJ Vaccines 3:37. https://doi.org/10.1038/s41541-018-0069-1.

37. Robert-Guroff M. 2016. The yin and yang of ADCC-mediating antibodies. EBioMedicine 3:10-11. https://doi.org/10.1016/j.ebiom.2016.01.003.

38. Terajima M, Co MD, Cruz J, Ennis FA. 2015. High antibody-dependent cellular cytotoxicity antibody titers to H5N1 and H7N9 avian influenza A viruses in healthy US adults and older children. J Infect Dis 212:1052-1060. https://doi .org/10.1093/infdis/jiv181.

39. Tomcikova K, Vareckova E. 2019. Different mechanisms of the protection against influenza $A$ infection mediated by broadly reactive HA2specific antibodies. Acta Virol 63:347-365. https://doi.org/10.4149/av 2019408.

40. Sun J, Braciale TJ. 2013. Role of T cell immunity in recovery from influenza virus infection. Curr Opin Virol 3:425-429. https://doi.org/10.1016/j.coviro .2013.05.001.

41. Christensen JP, Doherty PC, Branum KC, Riberdy JM. 2000. Profound protection against respiratory challenge with a lethal H7N7 influenza A virus by increasing the magnitude of CD8(+) T-cell memory. J Virol 74:11690-11696. https://doi.org/10.1128/JVI.74.24.11690-11696.2000.

42. Mohn KGI, Zhou F, Brokstad KA, Sridhar S, Cox RJ. 2017. Boosting of cross-reactive and protection-associated T cells in children after live attenuated influenza vaccination. J Infect Dis 215:1527-1535. https://doi.org/10.1093/infdis/ jix165.

43. Nienen M, Stervbo U, Molder F, Kaliszczyk S, Kuchenbecker L, Gayova L, Schweiger B, Jurchott K, Hecht J, Neumann AU, Rahmann S Westhoff T, Reinke P, Thiel A, Babel N. 2019. The role of pre-existing cross-reactive central memory CD4 T-cells in vaccination with previously unseen influenza strains. Front Immunol 10:593. https://doi.org/ 10.3389/fimmu.2019.00593.

44. Liu J, Stevens DJ, Haire LF, Walker PA, Coombs PJ, Russell RJ, Gamblin SJ, Skehel JJ. 2009. Structures of receptor complexes formed by hemagglutinins from the Asian Influenza pandemic of 1957. Proc Natl Acad Sci U S A 106:17175-17180. https://doi.org/10.1073/pnas.0906849106.

45. Okuno Y, Isegawa Y, Sasao F, Ueda S. 1993. A common neutralizing epitope conserved between the hemagglutinins of influenza $A$ virus $\mathrm{H} 1$ and H2 strains. J Virol 67:2552-2558. https://doi.org/10.1128/JVI.67.5 .2552-2558.1993.

46. Lu Y, Welsh JP, Swartz JR. 2014. Production and stabilization of the trimeric influenza hemagglutinin stem domain for potentially broadly protective influenza vaccines. Proc Natl Acad Sci U S A 111:125-130. https:// doi.org/10.1073/pnas.1308701110.

47. Cull MGS, J P. 2000. Biotinylation of proteins in vivo and in vitro using small peptide tags. Methods Enzymol 326:430-440. https://doi.org/10.1016/s0076 $-6879(00) 26068-0$.

48. Green TD, Montefiori DC, Ross TM. 2003. Enhancement of antibodies to the human immunodeficiency virus type 1 envelope by using the molecular adjuvant C3d. J Virol 77:2046-2055. https://doi.org/10.1128/jvi.77.3 .2046-2055.2003.

49. World Health Organization. 2011. Manual for the laboratory diagnosis and virological surveillance of influenza. World Health Organization, Geneva, Switzerland. 